\title{
Fatores críticos de sucesso na produção de frango de corte a partir da percepção do produtor integrado da região da Grande Dourados/MS
}

\author{
Critical success factors in the production of broilers from the perception of \\ the integrated producer of the region of Grande Dourados/MS
}

\author{
Sulma Vanessa Souza ${ }^{1}$ (D) Érika Rosendo de Sena Gandra ${ }^{2}$ [D , José Francisco dos Reis Neto ${ }^{3}$ (D), \\ Rodrigo Garófallo Garcia ${ }^{4}$ (1) \\ ${ }^{1}$ Universidade Estadual de Mato Grosso do Sul (UEMS), Ponta Porã (MS), Brasil. E-mail: souzavanessasvs@bol.com.br \\ ${ }^{2}$ Universidade Federal do Sul e Sudeste do Pará (UNIFESSPA), Xinguara (PA), Brasil. E-mail: erikagandra@unifesspa.edu.br \\ ${ }^{3}$ Universidade Anhanguera Uniderp, Campo Grande (MS), Brasil. E-mail: jose.rneto@anhanguera.com \\ ${ }^{4}$ Universidade Federal da Grande Dourados (UFGD), Dourados (MS), Brasil. E-mail: rodrigogarcia@ufgd.edu.br
}

Como citar: Souza, S. V., Gandra, E. R. S., Reis Neto, J. F., \& Garcia, R. G. (2021). Fatores críticos de sucesso na produção de frango de corte a partir da percepção do produtor integrado da região da Grande Dourados/MS. Revista de Economia e Sociologia Rural, 59(3), e226679. https://doi.org/10.1590/1806-9479.2021.226679

\begin{abstract}
Resumo: Objetivou-se analisar os fatores críticos de sucesso na produção de frango de corte sob a ótica do produtor integrado na região da Grande Dourados, Mato Grosso do Sul, Brasil. Metodologicamente, esta pesquisa é caracterizada como sendo descritiva, realizada com uma amostra composta por oito produtores integrados, residentes em municípios distintos: Caarapó, Dourados, Douradina, Glória de Dourados, Itaporã, Rio Brilhante e Vicentina. Para a coleta de dados, utilizou-se um questionário estruturado desenvolvido de acordo com os aspectos: estruturais, mão de obra, gestão administrativa, controle financeiro, biosseguridade e parceria integrada (produtor agroindústria). Com o intuito de agrupar os produtores com características similares, foi utilizada a análise de cluster, pelo método de agrupamento hierárquico complete linkage. O estudo apontou a existência de dois clusters e os resultados demonstraram que, para o cluster 1, o aspecto biosseguridade (cuidados gerais com a saúde do frango, localização do aviário, isolamento e portaria) é considerado o de maior importância para se manter na atividade, sendo que esse cluster demonstrou pouca importância aos aspectos: mão-de-obra, gestão e controle financeiro. Os produtores do cluster 2 também deram maior importância ao aspecto biosseguridade (apenas para o quesito cama de frango) e pouca importância ao aspecto gestão.
\end{abstract}

Palavras-chave: avicultura de corte, cluster, integração.

\begin{abstract}
The objective was to analyze the critical success factors in the production of broilers from the perspective of the integrated producer in the region of Grande Dourados, Mato Grosso do Sul, Brasil. Methodologically, this research is characterized as being descriptive, carried out with a sample composed of 8 integrated producers, residing in different municipalities: Caarapó, Dourados, Douradina, Glória de Dourados, Itaporã, Rio Brilhante, and Vicentina. For data collection, a structured questionnaire was used, developed according to the following aspects: structural, labor, administrative management, financial control, biosecurity, and integrated partnership (producer - agribusiness). To group producers with similar characteristics, cluster analysis was used, using the complete linkage hierarchical grouping method. The study pointed to the existence of two clusters and the results showed that for cluster 1 , the aspect of biosecurity (general care for the health of the chicken, location of the poultry, isolation, and entrance) is considered the most important to remain in the activity. This cluster showed little importance to the aspects: hand- workforce, management, and financial control. Cluster 2 producers also gave greater importance to the biosecurity aspect (only for the chicken litter item) and gave little importance to the management aspect.
\end{abstract}

Keywords: broiler poultry, cluster, integration. 


\section{Introdução}

A indústria avícola é apontada como um importante setor para o agronegócio brasileiro (Paranhos et al., 2020). Atualmente, o país é considerado, em âmbito mundial, o maior exportador e o segundo maior produtor de carne de frango (Associação Brasileira de Proteína Animal, 2017). Esse desempenho é reflexo do processo de reestruturação industrial do setor, decorrente da adoção de novas tecnologias, do uso de um sistema eficiente de pesquisa e desenvolvimento (P\&D), da organização industrial em larga escala e da evolução das técnicas de manejo, nutrição e sanidade das aves, que ocorreram no Brasil entre os anos de 1970 e acentuaram-se nos anos de 1990, a partir da abertura da economia latino-americana (Schmidt \& Silva, 2018; Espíndola, 2012; Garcia \& Ferreira Filho, 2005).

Mediante esse novo cenário, as agroindústrias se dispersaram para outras regiões do país, em especial para a região Centro-Oeste (Rodrigues et al., 2015). Em relação ao estado de Mato Grosso do Sul, os principais fatores que impulsionaram a vinda dessas agroindústrias foram a localização geográfica estratégica (Rodrigues et al., 2015) e as presenças de mão de obra e de matéria-prima (soja, milho e insumos-base para a fabricação de ração).

Atualmente, o estado ocupa posição de destaque no cenário brasileiro, sendo apontado como o oitavo maior produtor e o sexto maior exportador no âmbito nacional (Associação Brasileira de Proteína Animal, 2017). A produção é realizada através do sistema integrado, firmado entre os produtores e as agroindústrias (Rodrigues et al., 2015). Estimase que $100 \%$ da produção do estado seja realizada através dessa forma de organização (Oliveira \& Caleman, 2017).

Esse sistema denomina o proprietário da granja de "integrado" e a empresa de "integradora" (Ziebert \& Shikida, 2004). Nesta parceria, a integradora é incumbida de fornecer o pinto de um dia, a ração, os medicamentos, o transporte das aves ao abatedouro, a assistência técnica, entre outros (Figueiredo et al., 2006). O produtor integrado, por sua vez, é responsável pelo fornecimento dos demais insumos necessários à condução da atividade (Rodrigues et al., 2015).

A presença da integradora tornou a atividade mais organizada, haja vista a implantação de boas práticas de manejo, além de tornar a atividade acessível a vários produtores (Figueiredo et al., 2006). Por outro lado, houve uma dependência do produtor, uma centralização do poder de tomada de decisão por parte da indústria, assim como uma baixa remuneração do integrado (Richetti et al., 2002).

Não bastasse isso, os integrados atualmente necessitam lidar com alguns obstáculos ao sucesso de sua produção, dentre os quais cabe destacar: os aspectos estruturais (Simões et al., 2015), a falta de mão de obra especializada (Iguma \& Zen, 2017), a gestão (Hansen \& Mowen, 2003), o controle financeiro (Zanin et al., 2014), a biosseguridade (Sesti, 2004) e a parceira integrada (Ziebert \& Shikida, 2004).

Porém, quando bem administrados, esses fatores tendem a impactar positivamente nos resultados gerados pelo produtor. Um conceito bastante difundido na literatura, que permite ao produtor identificar os pontos-chave de sua atividade, é denominado de Fatores Críticos de Sucesso (FCS) (Donastorg et al., 2019; Bullen \& Rockart, 1981). FCS é definido como um número limitado de áreas cujos resultados satisfatórios permitem que a organização atinja seus objetivos (Bullen \& Rockart, 1981); portanto, essas áreas necessitam receber atenção contínua e meticulosa (Donastorg et al., 2019). Nesse sentido, este estudo objetivou analisar os fatores críticos de sucesso na produção de frango de corte sob a ótica do produtor integrado na região da Grande Dourados, Mato Grosso do Sul.

Esta pesquisa constitui-se de sete seções, incluindo a introdução recém-apresentada; a seção 2, que apresenta o panorama da avicultura de corte em Mato Grosso do Sul, Brasil; a seção 3, na qual é descrito o sistema integrado de produção; a seção 4, em que são delineados os fatores críticos de sucesso na produção de frango de corte em sistema integrado; a seção 5, na qual são descritos os materiais e métodos; a seção 6, em que são tecidos os resultados, e a seção 7, na qual são apresentadas as considerações finais. 


\section{Panorama da avicultura de corte em Mato Grosso do Sul, Brasil}

No período de 1970 a 1990, a avicultura de corte em Mato Grosso do Sul era desenvolvida em granjas autônomas, nas quais os abates eram realizados de forma manual pelos próprios granjeiros, cuja produção era designada para seu consumo ou para comercialização local, sendo a atividade caracterizada como artesanal (Mizusaki, 2009).

Sua expansão ocorreu no "final dos anos de 1980, com a perspectiva de priorizar a agricultura familiar, conforme declarações obtidas na época junto às empresas instaladas, como a COOAGRI, em 1990" (Mizusaki, 2007, p. 137). Os fatores que contribuíram para a instalação das agroindústrias no estado foram: disponibilidade de milho e soja, existência de mão de obra, localização estratégica do estado e presença de incentivos financeiros (Rodrigues et al., 2015).

A disponibilidade de soja e milho foram fatores importantes para que a agroindústria se instalasse nessa região, por serem os principais insumos utilizados na avicultura de corte (Rodrigues et al., 2015). No que se refere à existência de mão de obra, essa disponibilidade foi ocasionada, sobretudo, pela presença de mão de obra familiar no estado, que ocorreu em função da criação da Colônia Agrícola Nacional de Dourados (CAND) (Santana Júnior, 2009). Outro fator a ser mencionado é a localização estratégica de Mato Grosso do Sul, uma vez que o estado possui proximidade com os grandes centros de consumo do país (Mato Grosso do Sul, 2017).

Com relação ao papel das políticas públicas, houve incentivos nos âmbitos federal, estadual e municipal. Na esfera federal, pode-se destacar o Fundo Constitucional do CentroOeste (Superintendência do desenvolvimento do Centro Oeste, 2016). Em relação à política estadual de Mato Grosso do Sul e de seus municípios, destacam-se as de cunhos fiscais e tributários (Rodrigues et al., 2015; Mizusaki, 2009).

No período recente, Mato Grosso do Sul apresenta-se entre os 10 maiores produtores do Brasil, ocupando, em 2018, o oitavo lugar no quesito produção (452 mil toneladas de carne produzidas) e o sexto estado, no mesmo período, com maior importância na exportação de aves (Empresa Brasileira de Pesquisa Agropecuária, 2019). Atualmente, o estado dispõe de 1.225 aviários provenientes de 497 produtores ativos integrados a um dos cinco frigoríficos existentes no estado (Tabela 1). Os aviários estão instalados em 27 municípios, em sua maioria pertencentes à Microrregião de Campo Grande e à Microrregião de Dourados (Agência de Desenvolvimento Agrário e de Extensão Rural, 2019; Mato Grosso do Sul, 2017; Superintendência Federal de Agricultura de Mato Grosso do Sul, 2013).

Tabela 1- Municípios produtores de frango de MS, entre 2014 e 2018, por número de animais (milhões de aves)

\begin{tabular}{ccccccc} 
Ordem de participação & $\mathbf{2 0 1 4}$ & $\mathbf{2 0 1 5}$ & $\mathbf{2 0 1 6}$ & $\mathbf{2 0 1 7}$ & $\mathbf{2 0 1 8}$ & $\begin{array}{c}\text { Participação } \\
\text { média do } \\
\text { período } \\
\text { analisado }\end{array}$ \\
Sidrolândia & $\mathbf{4 2 , 8 6}$ & $\mathbf{4 7 , 0 4}$ & $\mathbf{4 5 , 1 2}$ & 49,36 & 46,60 & 46,19 \\
Dourados & 17,45 & 19,12 & 19,52 & 18,40 & 19,07 & 18,71 \\
Itaquiraí & 12,01 & 11,99 & 10,33 & 11,52 & 11,10 & 11,39 \\
Aparecida do Taboado & 7,10 & 8,14 & 9,63 & 8,71 & 8,10 & 8,34 \\
Itaporã & 6,60 & 7,05 & 8,65 & 8,33 & 7,59 & 7,64 \\
Fátima do Sul & 6,42 & 7,43 & 7,25 & 7,33 & 7,56 & 7,20 \\
Caarapó & 9,72 & 8,84 & 7,96 & 7,72 & 7,45 & 8,34 \\
Glória de Dourados & 6,23 & 6,71 & 6,00 & 5,81 & 7,12 & 6,37 \\
Iguatemi & 0,13 & 3,02 & 4,84 & 4,97 & 4,54 & 3,50 \\
Laguna Carapã & 2,04 & 2,17 & 2,50 & 3,86 & 3,76 & 2,87 \\
\hline
\end{tabular}

Fonte: Elaborado pelos autores a partir de dados do Serviço de Inspeção Federal (2019). 
Além de ser o maior produtor de aves do estado, Sidrolândia apresenta o maior volume de abates diários, em torno de 190.000 (cabeças/dia), seguida de Dourados, com 145.000 (cabeças/dia). Por outro lado, observa-se que o município de Dourados possui o maior número de produtores integrados, em torno de 145, enquanto Sidrolândia possui 136 produtores (Agência de Desenvolvimento Agrário e de Extensão Rural, 2019).

No que se refere ao número de postos de trabalho gerados, estima-se que cada aviário seja responsável por gerar, em média, dois empregos diretos e cinco indiretos, sendo a cadeia avícola responsável pela geração de 2.450 empregos diretos e 6.125 empregos indiretos (Agência de Desenvolvimento Agrário e de Extensão Rural, 2019).

\section{Sistema integrado de produção}

O sistema integrado de produção surgiu concomitantemente à modernização da avicultura, como processo de alterações nas estratégias organizacionais, disseminando-se rapidamente. Assim, a avicultura brasileira está baseada nesse sistema de produção, no qual as atividades do produtor são regidas por contratos firmados com a indústria (Richetti \& Santos, 2000).

Nesta parceria, a integradora se responsabiliza pelo fornecimento de pintos de um dia, ração, medicamentos, transporte de aves ao abatedouro, orientações e assistência técnica (Rodrigues et al., 2015); coordena a compra das matérias-primas usadas na fabricação da ração; realiza a seleção e a criação das matrizes que darão origem aos frangos de corte (carne), e sua distribuição aos pontos de venda, além de impor aos produtores o pacote tecnológico a ser adotado na produção, que inclui desde a genética utilizada até os padrões de manejo sanitário altamente sofisticados (Caldas et al., 2015; Araújo, 2009).

O produtor integrado é responsável pelas instalações e mão de obra, além de promover a limpeza e desinfecção do galpão após a retirada das aves, e prepará-lo para o recebimento de novo lote, atendendo impreterivelmente a todas as exigências técnicas da agroindústria (Richetti \& Santos, 2000).

As agroindústrias optam pelo processo de integração pela facilidade de obterem matériasprimas em quantidade, qualidade e tempo adequado ao ritmo do processo produtivo. Quanto aos produtores, estes decidem pela integração motivados pela garantia de escoamento do produto e pela possibilidade de uma produção ininterrupta (Figueiredo et al., 2006).

Os produtores que aderiram ao sistema de produção alternativa ficaram menos expostos às instabilidades do mercado, todavia tornaram-se dependentes da integradora, seja para fornecimento de matéria-prima e insumos, como também para a obtenção de assistência técnica (Sistema Brasileiro de Respostas Técnicas, 2007; Figueiredo et al., 2006). $\mathrm{Na}$ Figura 1, é possível visualizar as vantagens e desvantagens advindas do sistema de produção integrada para o produtor.

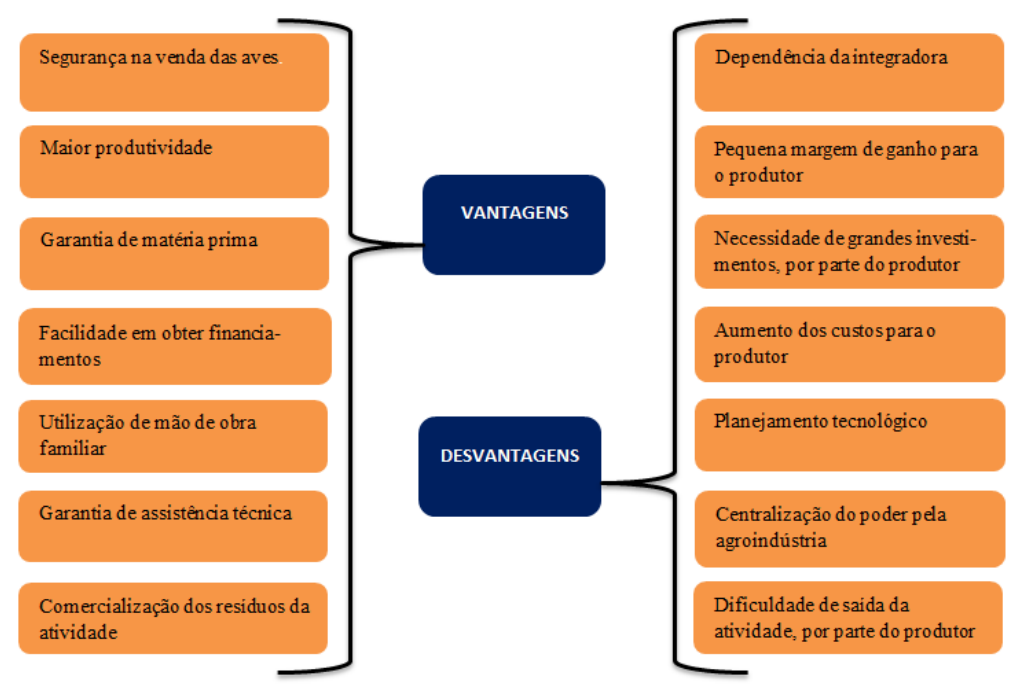

Figura 1- Vantagens e desvantagens do Sistema de Integração para os produtores integrados. Elaborado pelos autores a partir de Zaluski \& Marques (2015). 
Dentre as diversas vantagens, cabe destaque: a segurança na venda das aves a um valor previamente acordado, o que proporciona ao avicultor uma renda mensal; a utilização de mão de obra familiar e a qualificação profissional dessa mão de obra; maior produtividade ocasionada, sobretudo, pela assistência técnica advinda da agroindústria e pela facilidade de o produtor obter financiamentos e empréstimos bancários para investir na modernização de seus aviários (Marques, 2012). Outro ponto a ser mencionado é a possibilidade de este integrado incrementar sua renda a partir da comercialização dos resíduos da atividade (cama de frango) como adubo orgânico.

Como desvantagem, nota-se uma dependência destes produtores em relação à parceria integrada; logo, não podem comercializar seus produtos com outras empresas quando os preços de mercado estiverem acima dos pagos pelas integradoras (Marques, 2012) e esse panorama tende a limitar seus ganhos; há um cenário de centralização das tomadas de decisão por parte da integradora. Além disso, os avicultores necessitam investir constantemente em tecnologia, haja vista ser um dos critérios para se manter na parceria. Assim, os integrados endividam-se constantemente com o banco, fazendo com que sua saída da parceria seja dificultada, dada a amortização dos empréstimos ser, em geral, em longo prazo (Lima, 2004).

Diante desse cenário, para que este produtor possa se manter na atividade, deve efetuar um gerenciamento eficaz de sua propriedade, considerando a utilização de conceitos e ferramentas de planejamento estratégico.

\section{Fatores críticos de sucesso na produção de frango de corte em sistema integrado}

O conceito de Fatores Críticos de Sucesso (FCS) surgiu em 1961, a partir da publicação do trabalho Management Information Crisis, de D. Ronald Daniel (Stollenwerk, 2001). Esse estudo apontou que as instituições produzem uma quantidade expressiva de informações, todavia apenas uma pequena parcela destes dados auxilia os gestores na melhoria do desempenho, os quais foram denominados de FCS (Rockart, 1979).

FCS pode ser definido como sendo um número limitado de áreas em que os resultados satisfatórios asseguram um desempenho competitivo de sucesso para o indivíduo, o departamento ou a organização (Bullen \& Rockart, 1981), sendo considerado "os meios que garantem a realização dos objetivos da organização, ou seja, fatores que pela sua natureza podem comprometer todo o sucesso de um plano ou de uma estratégia" (Tarapanoff, 2001, p. 311).

Assim, estes fatores devem estar sob constante atenção da gerência, de modo a garantir um resultado final bem-sucedido, uma vez que são considerados os pontos-chave para o alcance do sucesso da organização (Rockart, 1979). Portanto, entende-se ser importante que as organizações conheçam os fatores que influenciam em seu êxito. No caso específico da produção de frango de corte em sistema integrado, um dos obstáculos que influenciam o sucesso da atividade são os aspectos estruturais. Observa-se a necessidade de o avicultor realizar constantes adaptações e inserção de novos modelos de produção (Simões et al., 2015). A tendência do setor é para adoção de sistema de produção cada vez mais eficiente, como o "Dark House".

Outro fator a ser mencionado é a falta de mão de obra qualificada, cuja sucessão está cada vez mais escassa no campo, dada a competitividade com as mais diversas indústrias, já que as indústrias tendem a absorver boa parte da mão de obra disponível, inclusive as do campo (Iguma \& Zen, 2017).

Quanto a gestão e controle financeiro, observa-se serem aspectos importantes na produção avícola (Zanin et al., 2014), pois seu correto gerenciamento fornece subsídios adequados para que o produtor possa planejar, controlar e tomar suas decisões estratégicas (Hansen \& Mowen, 2003). Entretanto, a gestão não deve se pautar unicamente nos custos, sendo necessário que contemple outros aspectos, como a gestão de pessoas. Para Ruberto et al. (2013), a execução correta da gestão rural, juntamente com a análise contábil bem estruturada, auxilia os produtores na tomada decisão, permitindo que estes obtenham maior produtividade e consequentes resultados satisfatórios, sejam estes econômicos ou financeiros. 
Outro aspecto que cabe atenção é a biosseguridade. Nota-se que os integrados necessitam ter uma maior atenção no que diz respeito aos programas de biosseguridade, uma vez que o crescimento e a modernização da indústria avícola acarretaram aumento do número de aves alojadas, o que se configura em uma situação favorável a multiplicação, disseminação e perpetuação de patógenos de aves, os quais promovem prejuízos econômicos (Sesti, 2004).

Por fim, cabe mencionar o contrato de integração, pois a ele estão relacionadas certas relações de desigualdades (Ziebert \& Shikida, 2004). Segundo fundamentos da Teoria da Agência, nessas situações em que uma das partes detém mais informações do que a outra em relação aos atributos transacionais, verifica-se que o elo que possui maior vantagem busca alinhar os interesses do agente aos seus (Zylbersztajn et al., 2015).

Para Kalamkar (2012), a parceria apresenta-se como um sistema de autorregulação, sistema de recompensa e punição (pago conforme a produção é realizada), no intuito de garantir a produção econômica de frangos de corte para o integrador. De acordo com Pinotti \& Paulillo (2006), esse tipo de contrato faz com que os pequenos produtores se tornem cada vez mais dependentes da agroindústria avícola, haja vista esta ser o principal canal de distribuição (em alguns casos, o único canal de distribuição).

Ademais, a saída do produtor da parceria integrada tende a ser dificultada, principalmente pelo longo prazo de amortização do capital inicial investido, além das incertezas que o mercado aviário apresenta (Lima, 2004). Esta situação de dependência implica na diminuição do poder de negociação do avicultor. Diante desse cenário, observase a necessidade de o produtor integrado buscar ferramentas que possam auxiliá-lo na gestão e organização de sua propriedade, principalmente as relacionadas ao apontamento dos fatores que influenciam no sucesso de seu negócio (Leidecker \& Bruno, 1991), pois, quando devidamente gerenciados, os FCS tendem a gerar impacto positivo sobre a organização (Rockart, 1979).

\section{Materiais e métodos}

Esta pesquisa é caracterizada como descritiva. De acordo com Vergara (1998, p. 45), "a pesquisa descritiva expõe características de determinada população ou de determinado fenômeno. Pode também estabelecer correlações entre variáveis e definir sua natureza". Uma de suas características está na utilização de técnicas padronizadas, como, por exemplo, a coleta de dados (Gil, 2008). Neste trabalho, utilizaram-se informações bibliográficas por meio de levantamento de literaturas em livros, dissertações, periódicos científicos, entre outros, e, a partir destas informações foi elaborado o questionário.

O estudo foi desenvolvido na região da Grande Dourados, no estado de Mato Grosso do Sul. Esta região é constituída atualmente por 11 municípios (Figura 2): Caarapó, Deodápolis, Dourados, Douradina, Fátima do Sul, Glória de Dourados, Itaporã, Jateí, Maracaju, Rio Brilhante e Vicentina (Mato Grosso do Sul, 2015).

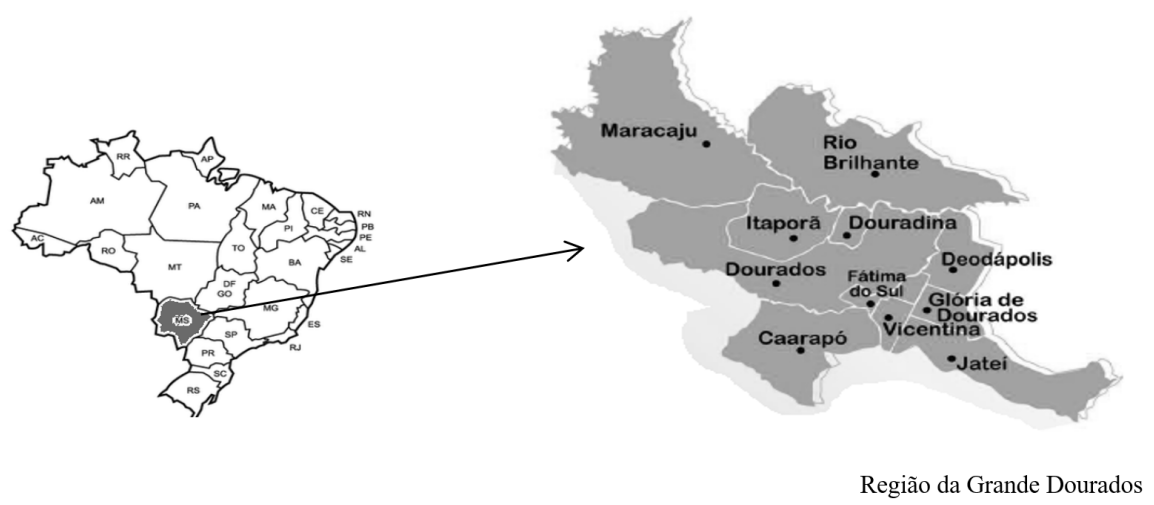

Figura 2 - Localização da Região da Grande Dourados, Mato Grosso do Sul, Brasil. Fonte: Adaptado de Instituto Brasileiro de Geografia e Estatística (2016); Mato Grosso do Sul (2015). 
Optou-se por realizar o estudo nessa região, haja vista a produção de frango de corte ser uma das principais atividades agroindustriais do estado, sendo considerado o sexto produto mais exportado de MS, em torno de 158 mil toneladas de carne de frango, em 2018 (Empresa Brasileira de Pesquisa Agropecuária, 2019), o que torna a região responsável por 39,08\% da produção total do estado (Serviço de Inspeção Federal, 2019). Estima-se que $100 \%$ da produção da região esteja vinculada à parceira integrada.

As fontes de dados utilizadas na pesquisa constituíram-se basicamente de dados primários. Os dados foram coletados por meio de entrevistas estruturadas com aplicação de um questionário contendo perguntas fechadas. Marconi \& Lakatos (2007) afirmam que a entrevista estruturada é realizada em formulário elaborado, sendo aplicado a um público previamente selecionado.

A técnica de amostragem utilizada neste estudo foi a amostragem por julgamento, por ser uma das técnicas não probabilísticas e que permite a seleção dos integrantes da entrevista com base no julgamento do entrevistador (Malhotra, 2006).

A amostra foi composta por oito produtores integrados (denominados de A, B, C, D, E, $\mathrm{F}, \mathrm{G}$ e H) de municípios e propriedades rurais distintos. A intenção de entrevistar produtores de municípios distintos pertencentes à região partiu do pressuposto de se buscar uma representatividade regional, haja vista haver homogeneidade das práticas produtivas e contratuais existentes entre os integrados e as incorporadoras da localidade. Dessa forma, foram entrevistados produtores dos munícipios de Caarapó, Dourados, Douradina, Glória de Dourados, Itaporã, Rio Brilhante e Vicentina. Esses sete munícipios juntos são responsáveis pela produção de $80,62 \%$ do total de frango produzido na região da Grande Dourados e de 31,50\% do total produzido em Mato Grosso do Sul (Serviço de Inspeção Federal, 2019).

O questionário utilizado foi composto por sete grupos de questões: (i) para caracterizar o perfil dos produtores (idade, sexo, nível de escolaridade e estado civil); (ii) para identificar as características estruturais e de produção (quantidades de aviários existentes, sistema de produção adotado, quantidade de frango produzido por lote, quantidade de lote alojado por ano e porcentagem de perda por lote (para os seis últimos lotes); (iii) três grupos de questões para conhecer como esses produtores realizam sua gestão (perguntas relacionadas à gestão de mão de obra, à estratégica e ao controle financeiro); (iv) para entender como é o relacionamento entre o integrado e a agroindústria, e, por fim, (v) um bloco contendo 66 quesitos para analisar os FCS (Apêndice 1), em que os aspectos analisados foram: estrutura, mão de obra, gestão administrativa, aspectos financeiros, biosseguridade e a parceria integrada (Produtor-Agroindústria). O questionário foi aplicado entre os meses de fevereiro e abril de 2018.

Cada questão para analisar os FCS permitia que o respondente escolhesse uma alternativa em escala de respostas do tipo "Likert", sendo: 7 = extremamente importante; 6 = muito importante; 5 = importante; 4 = indiferente; 3 = importância mediana; 2 = pouco importante; 1 = sem nenhuma importância. Diante disso, a pontuação de cada um dos aspectos propostos foi dada pela média das pontuações das questões que o compõem. Assim, a escala varia entre 1 e 7 pontos, sendo que quanto maior, maior é a importância atribuída pelos produtores ao aspecto em questão.

\subsection{Análise descritiva}

Para descrição dos resultados, foram utilizadas a frequência absoluta e a porcentagem para as variáveis categóricas. A frequência absoluta $\left(n_{i}\right)$ é dada pelo número de vezes em que uma variável assume um determinado valor/categoria em questão. A porcentagem $\left(p_{i}\right)$ é o resultado da razão entre a frequência absoluta e o tamanho da amostra, multiplicado por 100 , isto é, $100 \cdot \frac{n_{i}}{n} \%$.

Observa-se que as pontuações de cada aspecto e geral foram descritas pela média aritmética simples, desvio padrão, mediana, $1^{\circ}(\mathrm{Q} 1)$ e $3^{\circ}(\mathrm{Q} 3)$ quartis. A média aritmética simples é dada por $\bar{x}=\frac{1}{n} \sum_{i=1}^{n} x_{i}$, em que $x_{1}, \ldots, x_{n}$ são os $n$ valores de uma determinada variável $X$, o desvio padrão é dado por $s=\sqrt{\frac{1}{n-1} \sum_{i=1}^{n}\left(x_{i}-\bar{x}\right)^{2}}$ e os quartis Q1, mediana e Q3 
representam os valores que dividem os dados de forma que $25 \%, 50 \%$ e $75 \%$ das observações estarão abaixo dele, respectivamente.

\subsection{Análise de cluster}

Com o objetivo de sistematizar os produtores em grupos que apresentam características similares, foi utilizada a análise de cluster, pelo método de agrupamento hierárquico complete linkage e pela utilização da medida de distância euclidiana (Hair et al., 2009).

A adesão a este método de agrupamento (complete linkage) foi feita em virtude de não se ter o conhecimento do número de grupos entre os quais os produtores iriam ser divididos. Sua utilização permitiu que se encontrassem clusters semelhantes por meio de um critério de proximidade baseado na distância máxima entre objetos de dois clusters (a distância entre os membros mais diferentes de cada cluster). Em cada estágio da aglomeração, os dois grupos com a menor distância máxima (mais semelhantes) são combinados (Hair et al., 2009).

Também foi construído um dendrograma para avaliar a proximidade das observações e selecionar o número de grupos. O dendrograma é uma representação gráfica dos resultados de um procedimento hierárquico em que cada objeto é distribuído em um eixo e o outro eixo retrata as etapas no procedimento hierárquico. Começando com cada objeto representado como um cluster separado, o dendrograma mostra graficamente como os clusters são combinados em cada etapa do procedimento até que todos estejam contidos em um único cluster (Hair et al., 2009).

A fim de medir a confiabilidade e consistência interna da escala utilizada, ou seja, avaliar a magnitude com que os itens do instrumento estão correlacionados, utilizou-se o Coeficiente Alfa de Cronbach (Cortina, 1993). Para determinar um número ótimo de clusters, foram considerados os índices pseudo $F$ de Calinski \& Harabasz (1974), que são dados pela razão da variância entre os clusters pela variância dentro dos clusters:

pseudo $F=\frac{(n-k)}{(k-1)} \frac{B_{k}}{W_{k}}$

Em que $n$ é o número de observações, $k$ é o número de clusters e $B_{K}$ e $W_{k}$ são as somas de quadrados entre (between) e dentro (within) dos clusters, respectivamente. Altos valores dos índices indicam clusters bem separados. Assim, os autores indicam que uma solução de cluster com o maior valor dessas estatísticas é considerada a melhor, uma vez que minimiza a variância dentro dos grupos e maximiza a variância entre grupos (Calinski \& Harabasz, 1974). A medida de distância considerada entre as pontuações dos produtores foi a euclidiana, expressa como:

$d=\sqrt{\sum_{i=1}^{n_{k}}\left(x_{i}-y_{i}\right)^{2}}$

Em que $n_{k}$ é o número de variáveis avaliadas e $x_{i}$ e $y_{i}$ são os valores das observações $x$ e $y$ para a $i$-ésima variável. Todas as análises foram realizadas com o auxílio do ambiente estatístico R (R Development Core Team, 2015), versão 3.3.1.

\section{Resultados e Discussão}

Esta seção está dividida em três tópicos. Na primeira parte, apresenta-se a caracterização dos produtores entrevistados e de sua estrutura de produção; na segunda, discute-se a análise dos Fatores Críticos de Sucesso: (i) aspectos estruturais e manejo, (ii) mão de obra, (iii) gestão, (iv) controle financeiro, (v) biosseguridade na produção avícola e (vi) parceria com a agroindústria. Por fim, na terceira parte, apresenta-se a formação dos clusters. 


\subsection{Caracterização dos produtores entrevistados e de sua estrutura de produção}

Dos oito produtores que compõem a amostra, todos são do sexo masculino (100\%). No que concerne à faixa etária, os respondentes estão distribuídos em três faixas de idade: de 41 a 50 anos (12,50\%), de 51 a 60 anos (75\%) e acima de 65 anos (12,50\%). Em relação ao estado civil, observa-se que mais da metade dos indivíduos são casados (87,50\%). No que se refere ao grau de escolaridade, nota-se que $37,50 \%$ possuem ensino superior, enquanto $12,50 \%$ apresentam formação técnica em agropecuária e 12,50\% possuem mestrado (Figura 3).
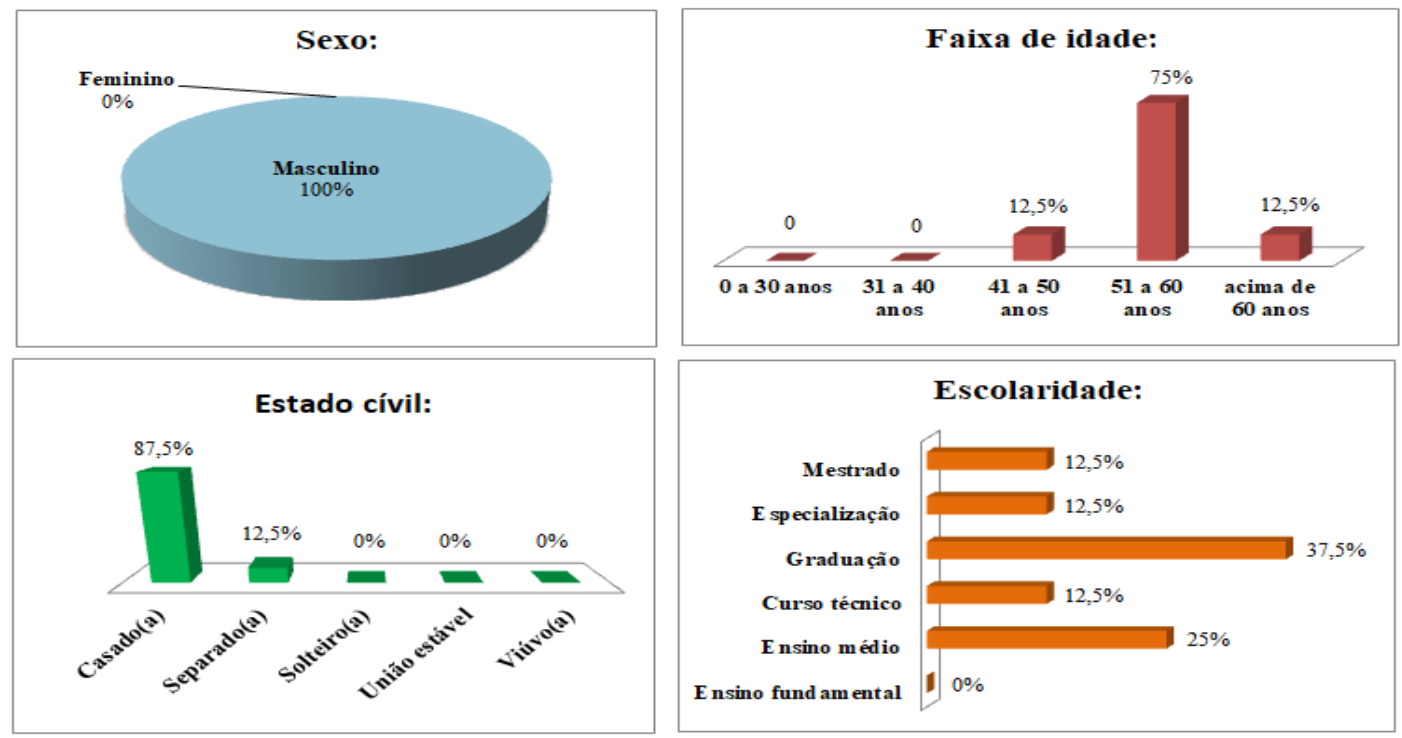

Figura 3 - Perfil dos entrevistados. Fonte: Elaborado pelos autores (2019).

Quanto à produção, constatou-se que os avicultores possuem de dois a seis aviários, em geral, e que os produtores da região possuem um modal (equivale a quatro aviários em sistema Dark House). Sobressaiu apenas o produtor F, o qual apresentou quatro modais (dezesseis aviários) do tipo Dark House (Tabela 2).

Tabela 2 - Características da produção de cada avicultor entrevistado

\begin{tabular}{|c|c|c|c|c|c|c|}
\hline Produtor & $\begin{array}{c}\text { Localização } \\
\text { da } \\
\text { propriedade }\end{array}$ & $\begin{array}{l}\text { Total de } \\
\text { aviários }\end{array}$ & $\begin{array}{c}\text { Sistema de } \\
\text { produção }\end{array}$ & $\begin{array}{l}\text { Capacidade de } \\
\text { alojamento por } \\
\text { lote (mil unid. } \\
\text { de pintos) }\end{array}$ & $\begin{array}{l}\text { Número de } \\
\text { alojamentos } \\
\text { por ano }\end{array}$ & $\begin{array}{c}(\%) \\
\text { de } \\
\text { perda } \\
\text { por } \\
\text { lote }\end{array}$ \\
\hline A & Caarapó & 4 & Dark House & 140.000 & 6 & $4 \%$ \\
\hline$B^{1}$ & Dourados & 6 & $\begin{array}{l}\text { Dark House } \\
\text { Convencional }\end{array}$ & $\begin{array}{l}140.000 \\
170.000\end{array}$ & 6 & $3,5 \%$ \\
\hline C & Douradina & 4 & Dark House & 140.000 & 6 & $4 \%$ \\
\hline D & $\begin{array}{l}\text { Glória de } \\
\text { Dourados }\end{array}$ & 4 & Dark House & 140.000 & 6 & $4 \%$ \\
\hline$E$ & Itaporã & 2 & Dark House & 54.000 & 6 & $3 \%$ \\
\hline $\mathrm{F}$ & Itaporã & 16 & Dark House & 132.000 & 5,25 & $4 \%$ \\
\hline$G^{2}$ & Rio Brilhante & 5 & $\begin{array}{l}\text { Dark House } \\
\text { Convencional }\end{array}$ & 110.000 & 6 & $4 \%$ \\
\hline $\mathrm{H}$ & Vicentina & 4 & Dark House & 138.000 & 5,7 & $4 \%$ \\
\hline
\end{tabular}

NOTA: (1) produtor B, possui um total de seis aviários, sendo dois em sistema convencional (aloja em torno de 30.000 pintos por lote) e quatro em sistema Dark House (aloja em torno de 140.000 pintos por lote). (2) produtor G, possui um total de cinco aviários, sendo dois em sistema convencional e três em sistema Dark House. Fonte: Elaborado pelos autores (2019). 
Do total dos produtores, cerca de 25\% iniciaram suas atividades entre 1991 e 1993, e possuem aviários no modelo convencional e Dark House (produtores B e G). Os demais (75\%) iniciaram sua atividade entre os anos de 2008 e 2015, e produzem apenas em sistema Dark House. O setor avícola da região apresenta tendência de transição dos aviários convencionais para os Dark House (produtores mais antigos, como é o caso dos produtores $B$ e G), tendo em vista que a tecnologia é considerada como elemento de destaque para que se obtenham elevados níveis de produtividade e de conversão alimentar (Richetti et al., 2002). Caso o produtor não tenha interesse em alterar a estrutura de seu aviário, seu contrato é encerrado.

No que se refere à média de frangos produzidos por lote, constatou-se que a produção no sistema convencional é de 30.000 aves por lote; já no sistema Dark House, a média varia de 132.000 a 140.000 aves por lote. Em ambas as propriedades, verificou-se que são alojados em torno de 5,25 a 6 lotes anuais. No quesito volume de perdas por lote, foi apurado que este se manteve em torno de 3 a 4\%, margem de perda considerada normal tanto para os avicultores quanto para as agroindústrias. Essas perdas ocorrem principalmente por refugos, mortes naturais, anomalias, infarto (morte súbita) e doenças respiratórias.

No que tange à gestão, buscou-se analisar a gestão da mão de obra, a estratégica e o controle financeiro (Figura 4). Em relação à mão de obra, observa-se que nenhum produtor utiliza exclusivamente mão de obra familiar, ainda que $12,5 \%$ dos respondentes tenham informado que não possuem empregados fixos e que a atividade do dia a dia é realizada por familiares (esposa, filhos, etc.). Nota-se que o produtor E, diversamente, afirma que se utiliza de mão de obra temporária, em geral, para preparação das instalações, em período de alojamento dos pintainhos, remoção da cama e limpeza das instalações no intervalo entre lotes. Cerca de $87,5 \%$ dos entrevistados possuem empregados fixos, em média de um a quatro empregados fixos por propriedade.

Quanto à qualidade do emprego, nota-se que $87,5 \%$ dos entrevistados dispõem registro em carteira aos seus funcionários, destacando que o emprego gerado está de acordo com as exigências da legislação brasileira - este é um quesito para serem mantidos na parceria integrada -, a qual prevê registro em carteira, ausência de emprego infantil e jornadas semanais de até 44 horas. Os demais respondentes (12,5\%) não disponibilizam registro, por não possuírem empregados fixos. No quesito participação em treinamentos, $100 \%$ dos respondentes disponibilizam curso e treinamento, sendo estes realizados pelos próprios produtores ou pela agroindústria.

Em relação aos benefícios e gratificações, nota-se que $87,5 \%$ dos produtores oferecem algum tipo de benefício aos seus funcionários (auxílio moradia, alimentação, ajuda de custo e gratificação por produção) como forma de reter e motivar seus colaboradores. De acordo com Fagundes et al. (2018), o estado de Mato Grosso do Sul apresenta um cenário de ausência de mão de obra qualificada no setor rural. Assim, é importante que o integrado mantenha seus planos de benefícios e gratificações, posto que a insatisfação do trabalhador em relação à sua remuneração é fator prejudicial à dinâmica organizacional.

Quanto à utilização de equipamento de proteção individual (EPI), 100\% dos produtores enfatizam seu uso e disponibilidade aos funcionários, sendo esta uma exigência para se manter como integrado, assim como um meio de propiciar um ambiente laboral mais seguro, tanto para o integrado quanto para seus funcionários.

Em relação à gestão, observa-se que $75 \%$ dos produtores não possuem um modelo de planejamento estratégico a ser seguido, ou seja, realizam as mudanças de sua atividade conforme necessidade e exigência das integradoras. Esta situação apresenta-se como um fator negativo a estes integrados, haja vista o planejamento ser uma importante ferramenta de gestão, que permite aos gestores tomarem suas decisões pautadas em informações concretas e com menor risco e incerteza (Munaretto et al., 2019). Assim, de acordo com os autores supracitados, as propriedades rurais, no atual cenário, não devem ser abordadas como no passado, dada a existência de um mercado que se apresenta cada vez mais competitivo e com menores margens de lucros. 


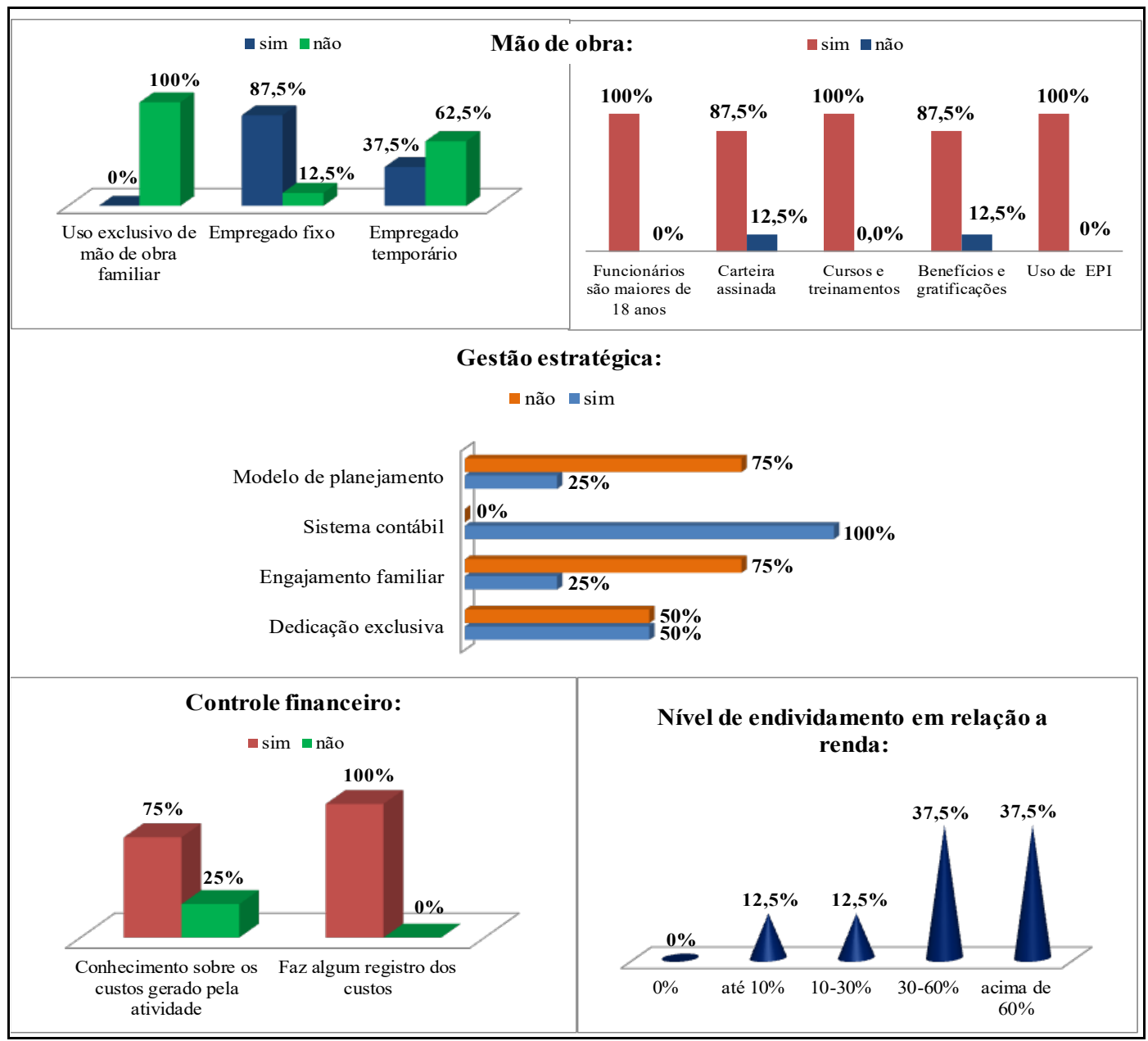

Figura 4 - Gestão: mão de obra, estratégica e controle financeiro. Fonte: Elaborado pelos autores (2019).

Dos entrevistados, $100 \%$ utilizam-se de sistema contábil e de orientações de um profissional contábil. Cerca de $50 \%$ dos integrados enfatizam dedicação exclusiva à atividade aviária, enquanto $50 \%$ dos respondentes informaram que desenvolvem atividades complementares, como piscicultura, produção de soja e criação de bovinos de corte.

Quanto ao controle financeiro, 75\% mencionam conhecer os custos (fixos ou variáveis) gerados por sua atividade. Dentre os itens que apresentam maiores custos operacionais, foram mencionados a energia elétrica e a mão de obra. Segundo um dos entrevistados, o gasto com energia elétrica representa em média 37\% dos custos operacionais anuais da propriedade e decorre, principalmente, da utilização do sistema de produção automatizado, enquanto a mão de obra representa 15\%. Para Bampi (2014), é importante que o produtor gerencie corretamente os custos de sua atividade de modo a verificar até que ponto é viável economicamente se manter na parceria integrada.

Todos os produtores entrevistados (A, B, C, D, E, F, G e H) informam que realizam os registros dos custos advindos de suas atividades, que geralmente são feitos em planilhas eletrônicas, livro contábil ou caderno escolar. Cerca de 100\% dos respondentes apresentam algum nível de endividamento (Figura 3), oriundo de financiamentos gerados para aquisição dos aviários Dark House, o que tende a dificultar sua saída da parceria, conforme apontado por um dos avicultores entrevistados.

No que se refere à relação entre integrado e integradora (Figura 5), observa-se que $62,5 \%$ dos produtores mencionam que a parceria proporcionou melhoria financeira, ainda que não tenha proporcionado estabilidade financeira - considerando-se o ano de entrada do produtor na atividade até o ano de 2018. 


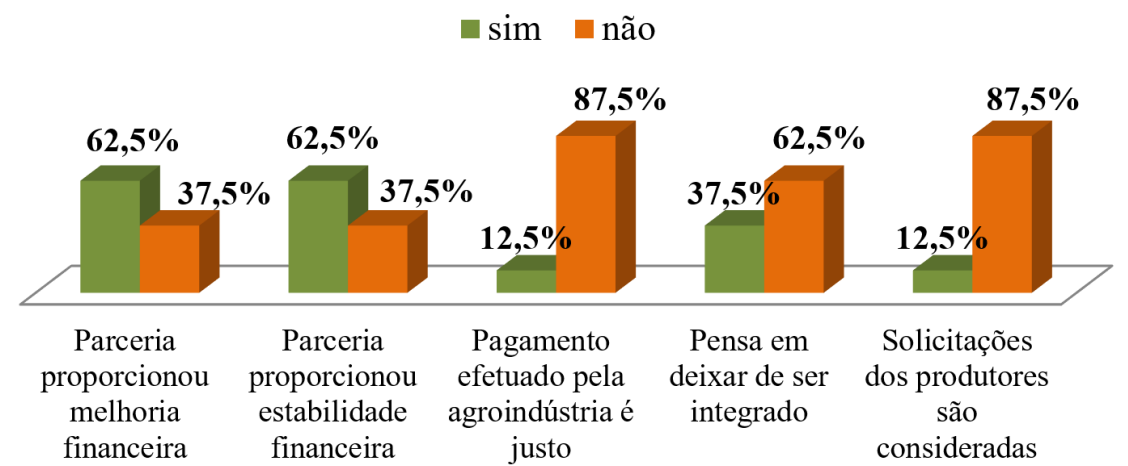

Figura 5 - Relacionamento integrado- integradora. Fonte: Elaborado pelos autores (2019).

Em torno de $87,5 \%$ dos produtores enfatizaram que o pagamento realizado pela agroindústria está abaixo do desejado, haja vista as planilhas de custeio não serem atualizadas constantemente pela agroindústria. Resultados distintos foram obtidos nos estudos de Ziebert \& Shikida (2004), que constataram que $75 \%$ dos produtores integrados salientaram serem remunerados adequadamente, e de Guareski et al. (2019), que identificaram que $100 \%$ dos produtores que participaram de sua pesquisa estão satisfeitos com o valor recebido pelo desenvolvimento da atividade.

Para os avicultores, além de as agroindústrias atualizarem constantemente as planilhas de precificação, elas devem detalhar melhor os custos de produção, uma vez que os avicultores não participam da pesagem e contagem das aves entregues às agroindústrias (Associação de avicultores da zona da Mata, 2014). Em consonância, Guareski et al. (2019) sugerem em seu estudo a necessidade de as integradoras manterem os produtores informados sobre os diversos custos que englobam a atividade, de modo que estes possam realizar uma análise comparativa entre os valores cobrados pelos insumos no mercado e os valores do quilo de frango comercializado extraintegração.

Apesar do descontentamento dos avicultores entrevistados no quesito pagamento $(62,5 \%)$, eles não pensam em deixar de serem produtores integrados, pois a parceria proporciona vantagens, como fornecimento de todos os insumos necessários à produção, assistência técnica e segurança na venda dos frangos produzidos. Tais vantagens são apontadas nos estudos realizados por Guareski et al. (2019), Zaluski \& Marques (2015), Figueiredo et al. (2006) e Ziebert \& Shikida (2004).

Em relação às desvantagens da integração, destacam-se: a burocracia, a baixa remuneração, o monopólio por parte da integradora e a pouca ou nenhuma influência dos produtores nas decisões. Conforme relato de um dos produtores entrevistados: "... quem manda e comanda é a integradora. Não há flexibilidade e se não produzir com ela, não tem outra alternativa para escolher: ou produz com ela, ou sai da atividade e assume os prejuízos sobre o investimento". Em consonância, Otsuka et al. (2016) salientam que, nesse tipo de contrato, as decisões de gerenciamento de produção são rigorosamente controladas pela integradora, dada a autonomia que esta possui sobre a produção.

Dentro deste contexto, constata-se que a produção de frango da região da Grande Dourados pode ser considerada concentrada. Conforme os estudos realizados por Barzel (2005), Williamson (1985) e Zylbersztajn (1995), esta característica tende a gerar conflitos devido à diferença de poder de barganha e promover, em longo prazo, insustentabilidade do sistema, caso não haja possíveis intervenções.

\subsection{Análise dos fatores críticos de sucesso (FCS)}

As frequências das respostas relatadas pelos produtores que participaram desta pesquisa demonstraram que, para todos os itens questionados aos respondentes, pelo menos metade deles relatou que os fatores eram importantes, muito importantes ou extremamente importantes para o sucesso do produtor integrado de frango de corte, sobretudo para os aspectos de "Iocalização do aviário, isolamento e portaria" e "cuidados 
gerais com a saúde dos frangos", para os quais nenhum entrevistado atribuiu importância mediana ou inferior a cada um dos itens avaliados. Calculando a pontuação entre os diferentes aspectos, os seguintes resultados foram obtidos:

Tabela 3 - Medidas descritivas da pontuação dos diferentes aspectos pelos participantes da pesquisa

\begin{tabular}{cccccc} 
Aspecto & Média & Desvio Padrão & Mediana & Q1 & Q3 \\
1. Estrutura e manejo & 6,66 & 0,33 & 6,75 & 6,44 & 6,91 \\
2. Mão de obra & 4,94 & 2,52 & 5,88 & 4,00 & 6,81 \\
3. Gestão & 5,47 & 0,88 & 5,44 & 4,84 & 5,94 \\
4. Controle financeiro & 5,77 & 1,63 & 6,42 & 5,63 & 6,75 \\
5.1. Localização do aviário, isolamento e portaria & 6,88 & 0,19 & 7,00 & 6,79 & 7,00 \\
5.2. Cuidados gerais com a saúde dos frangos & 6,89 & 0,14 & 6,94 & 6,84 & 7,00 \\
5.3. Limpeza e desinfecção & 6,63 & 0,49 & 6,83 & 6,42 & 7,00 \\
5.4. Cama do aviário & 6,75 & 0,33 & 6,83 & 6,67 & 7,00 \\
5.5. Higiene e segurança do trabalhador & 5,50 & 1,55 & 5,64 & 4,68 & 7,00 \\
6. Parceria com a agroindústria & 6,41 & 0,87 & 6,71 & 6,25 & 7,00 \\
Geral & 6,19 & 1,28 & 6,71 & 6,00 & 7,00 \\
\hline
\end{tabular}

Fonte: Elaborado pelos autores (2019).

Nota-se na Tabela 3 que as pontuações relacionadas a "gestão", "higiene e segurança do trabalhador" e "mão de obra" apresentaram as menores médias e medianas entre todos os aspectos considerados, o que indica que são os fatores para os quais os entrevistados atribuem menores importâncias, sendo as médias de 5,47, 5,50 e 4,94 pontos, e as medianas de 5,44, 5,64 e 5,88 pontos, respectivamente. Por outro lado, os aspectos "localização do aviário, isolamento e portaria" e "cuidados gerais com a saúde dos frangos" caracterizam-se como os aspectos para os quais os produtores mais dão importância, com pontuações médias de 6,88 e 6,89 pontos, e medianas de 7,00 e 6,94 pontos, respectivamente. A pontuação média geral, considerando todos os aspectos avaliados, é de 6,19 pontos.

Em seguida, avaliou-se a pontuação geral por entrevistado, verificando-se que as menores pontuações são observadas para o produtor (B) e para o produtor (D), ambas inferiores a 6 pontos, indicando que os mesmos tendem a dar menor importância para os aspectos avaliados em relação aos demais produtores (Figura 6).

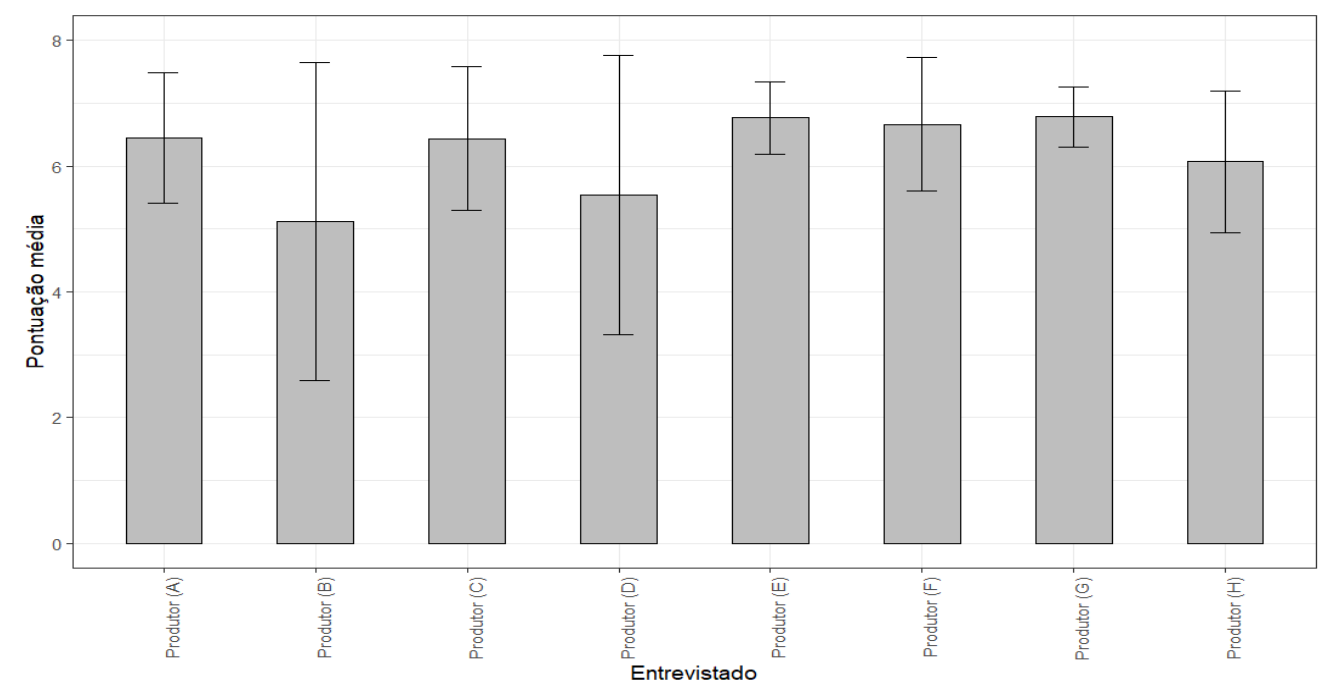

Figura 6 - Pontuações gerais (média e desvio padrão) dos participantes da pesquisa. Fonte: Elaborado pelos autores (2019). 


\subsection{Análise de cluster}

Ao realizar-se a análise de cluster aplicada às pontuações por aspecto dos oito produtores participantes da pesquisa, foi possível obter os índices de Calinski-Harabasz (CH index) para os diferentes números de cluster (Tabela 4).

Tabela 4 - Índices de Calinski-Harabasz da análise de cluster aplicada às variáveis gerais da pesquisa, para diferentes números de cluster

\begin{tabular}{ccc} 
Número de clusters & CH index \\
2 & 22,86 \\
3 & 18,84 \\
4 & 20,75 \\
5 & 17,48 \\
\hline
\end{tabular}

Fonte: Elaborado pelos autores (2019).

Assim, nota-se, na Tabela 4, que o índice foi maior para o agrupamento em dois clusters, indicando o número ótimo de clusters dentre os quais as observações serão divididas.

Observa-se, no dendrograma apresentado na Figura 7, a divisão dos produtores participantes da pesquisa entre os dois clusters considerados. O primeiro cluster é composto por dois entrevistados: sendo um de Dourados e um de Glória de Dourados; já o segundo é composto por seis entrevistados, sendo um de Douradina, dois de Itaporã, um de Rio Brilhante, um de Caarapó e um de Vicentina.

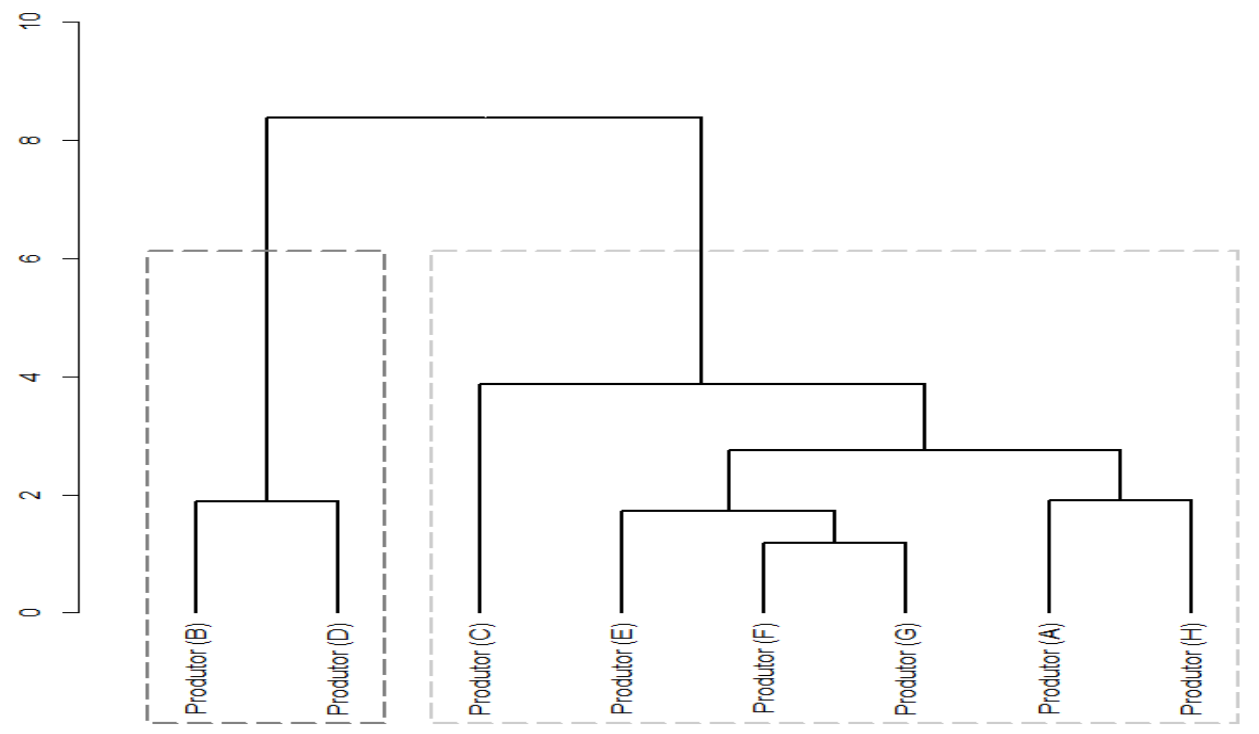

Figura 7 - Dendrograma da análise de cluster aplicada às pontuações por aspecto. Fonte: Elaborado pelos autores (2019).

\section{Cluster 1}

As pontuações por aspecto dos produtores alocados no cluster 1 (Tabela 5) demonstram que, para maior parte dos aspectos avaliados, a pontuação média obtida pelos produtores alocados no primeiro cluster é inferior às observadas na Tabela 3, no que se refere a todos os entrevistados. Consequentemente, a importância atribuída a tais itens é menor, sendo que as pontuações são maiores apenas para os aspectos "localização do aviário, isolamento e portaria", "cuidados gerais com a saúde dos frangos" e "parceria com a agroindústria". 
De acordo com este resultado, pode-se constatar que a maior importância dada por esse cluster está no subaspecto "cuidados gerais com a saúde dos frangos" $(6,94)$, resultado este que pode ser explicado pela influência que a produção final tem sobre o pagamento a ser recebido pelo produtor, uma vez que o produtor possui metas a serem atingidas, principalmente no que tange ao peso médio final, à conversão alimentar e à idade. De acordo com Oliveira \& Caleman (2017), a indústria processadora impõe um rol de exigências relacionadas à criação, como tempo médio de abate (em torno de 43 dias). Logo, a desatenção do produtor a esse quesito gera perdas em sua remuneração.

A mortalidade deve estar em torno de até $4 \%$, pois, acima disso, a agroindústria desconta do produtor os excedentes. Além disso, há uma margem de tolerância por parte dos abatedouros em alguns quesitos (calo no pé, dermatite, papo cheio, caquéticos, animais desidratados, etc.), que podem gerar desconto no valor final a ser pago ao integrado. $\mathrm{Na}$ percepção de Caldas et al. (2015), o produtor possui uma participação mínima na formação dos preços pagos pelas aves, haja vista os valores percebidos estarem condicionados ao desempenho zootécnico auferido em cada lote produzido, "assim sendo, de acordo com o desempenho das aves, o integrado pode ser bonificado ou penalizado em sua remuneração" (Caldas et al., 2015, p. 353).

Tabela 5 - Medidas descritivas da pontuação nos diferentes aspectos dos participantes da pesquisa

\begin{tabular}{cccccc} 
Aspecto & Média & Desvio Padrão & Mediana & Q1 & Q3 \\
1. Estrutura e manejo & 6,44 & 0,44 & 6,44 & 6,28 & 6,59 \\
2. Mão de obra & 1,00 & 0,00 & 1,00 & 1,00 & 1,00 \\
3. Gestão & 4,50 & 0,35 & 4,50 & 4,38 & 4,63 \\
4. Controle financeiro & 3,25 & 1,06 & 3,25 & 2,88 & 3,63 \\
5.1. Localização do aviário, isolamento e portaria & 6,92 & 0,12 & 6,92 & 6,88 & 6,96 \\
5.2. Cuidados gerais com a saúde dos frangos & 6,94 & 0,09 & 6,94 & 6,91 & 6,97 \\
5.3. Limpeza e desinfecção & 6,33 & 0,24 & 6,33 & 6,25 & 6,42 \\
5.4. Cama do aviário & 6,33 & 0,47 & 6,33 & 6,17 & 6,50 \\
5.5. Higiene e segurança do trabalhador & 3,29 & 0,00 & 3,29 & 3,29 & 3,29 \\
6. Parceria com a agroindústria & 6,43 & 0,20 & 6,43 & 6,36 & 6,50 \\
Geral & 5,14 & 2,00 & 6,15 & 3,82 & 6,69 \\
\hline
\end{tabular}

Fonte: Elaborado pelos autores (2019).

O aspecto "mão de obra" obteve média 1,00, sendo considerado dentre os seis aspectos analisados nesse cluster como o de menor importância, em função de conseguirem gerir adequadamente sua mão de obra nos seguintes aspectos: falta de mão de obra, falta de mão de obra qualificada, elevada rotatividade/absenteísmo e ausência de comprometimento dos funcionários. Os produtores salientam dispor aos seus funcionários benefícios, gratificações e um ambiente propício à qualidade de vida, com o propósito de os manterem na propriedade.

Os aspectos "gestão" $(4,50)$ e "controle financeiro" $(3,25)$ apresentaram as menores médias. Em relação à gestão, os entrevistados salientaram que, em função de executarem a atividade com seus familiares (esposa e filhos/as), fazem anotação "em cadernos" e demonstram saber da importância de registrar os custos de produção. Entretanto, não veem necessidade na utilização de computadores para tais fins; ademais, um dos produtores relatou não ter nenhum conhecimento em informática, o que inviabiliza a utilização desse equipamento.

Quanto ao aspecto "controle financeiro", sua média baixa resultou devido aos produtores darem pouca importância a itens, como: dispêndio com impostos e tributação; custo com mão de obra, e custo com conservação e reparo. Para os entrevistados, o item "dispêndio com imposto e tributação" é irrelevante, uma vez que os pagamentos dos impostos são obrigatórios por lei. Já em relação ao item "custo com conservação e reparos", 
na maioria das vezes, os produtores efetuam os reparos dos aviários, não possuindo custo para contratar um profissional para efetuar tais reparos. Para Zanin et al. (2014, p. 10), "gerir os custos das atividades praticadas dentro de uma empresa é fundamental para qualquer ramo de negócio", ou seja, de acordo com o autor, o sucesso de qualquer empresa rural está diretamente relacionado ao controle dos custos.

\section{Cluster 2}

Ao contrário do observado no primeiro cluster, a importância atribuída pelos produtores do cluster 2 (Tabela 6) aos itens avaliados tende a ser maior que a observada na amostra geral, pois as pontuações médias são maiores, exceto para os domínios "Localização do aviário, isolamento e portaria", "Cuidados gerais com a saúde dos frangos" e "Parceria com a agroindústria".

Tabela 6 - Medidas descritivas da pontuação dos diferentes aspectos pelos participantes da pesquisa

\begin{tabular}{cccccc} 
Aspecto & Média & Desvio Padrão & Mediana & Q1 & Q3 \\
1. Estrutura e manejo & 6,73 & 0,30 & 6,81 & 6,56 & 6,97 \\
2. Mão de obra & 6,25 & 0,81 & 6,38 & 5,81 & 6,94 \\
3. Gestão & 5,79 & 0,74 & 5,75 & 5,34 & 6,06 \\
4. Controle financeiro & 6,61 & 0,34 & 6,58 & 6,38 & 6,92 \\
5.1. Localização do aviário, isolamento e portaria & 6,86 & 0,22 & 7,00 & 6,75 & 7,00 \\
5.2. Cuidados gerais com a saúde dos frangos & 6,88 & 0,16 & 6,94 & 6,78 & 7,00 \\
5.3. Limpeza e desinfecção & 6,72 & 0,53 & 7,00 & 6,75 & 7,00 \\
5.4. Cama do aviário & 6,89 & 0,14 & 6,92 & 6,83 & 7,00 \\
5.5. Higiene e segurança do trabalhador & 6,24 & 0,86 & 6,36 & 5,61 & 7,00 \\
6. Parceria com a agroindústria & 6,40 & 1,02 & 6,93 & 6,32 & 7,00 \\
Geral & 6,54 & 0,65 & 6,85 & 6,23 & 6,85 \\
\hline
\end{tabular}

Fonte: Elaborado pelos autores (2019).

Verifica-se que a melhor média obtida nesse cluster foi a do subaspecto "Cama do aviário" (6,89), o qual faz parte do aspecto biosseguridade. A média nesse subaspecto ocorreu em função da grande importância que ambos os produtores dão ao aspecto biosseguridade, haja vista o cumprimento das normas de biosseguridade ser uma exigência na continuidade da parceria integrada com a agroindústria. Além disso, na visão Kneipp (2013, apud Amaral et al 2014, p. 665), “o impacto econômico das doenças, para a avicultura, pode ser crucial para a manutenção do negócio, quando teríamos perdas por mortalidade, redução dos resultados de desempenho", entre outros fatores.

Para Figueiredo et al. (2006), a atividade apresenta uma baixa rentabilidade - a cada real investido, o produtor tem apenas $\mathrm{R} \$ 1,30$ de retorno -, sendo passível de prejuízos. Portanto, é necessário que o produtor esteja em constante atenção aos custos, no intuito de minimizar suas falhas de manejo.

Dentre os aspectos analisados, observa-se que a "gestão" $(5,79)$, foi apontada como o de menor importância quando comparado aos demais. Tal resultado decorre em função dos itens: dedicação exclusiva da atividade aviária, conhecimento em tecnologia e inovação em aviários; uso de computadores como ferramenta de controle financeiro e gestão; pessoas serem consideradas pelos entrevistados como tendo pouca importância ou nenhuma, para que se tenha um desempenho eficaz nas suas atividades.

Para os respondentes, a utilização ou não de computadores para efetuar relatórios financeiros não influencia na excelência da produção de frango, dado que o controle financeiro pode ser feito naturalmente em livro caixa ou anotações em cadernos. Na visão do produtor, ter conhecimento ou não em tecnologia e inovação não repercute no sucesso de sua produção, uma vez que alguns dos entrevistados ainda utilizam aviários do tipo 
convencional e afirmam obterem resultados satisfatórios, embora sejam menores, quando comparados aos obtidos nos aviários Dark House.

Em dissonância, Ziebert \& Shikida (2004, p. 83) relataram que 45,8\% dos produtores entrevistados em seu estudo "visam investimentos em inovações tecnológicas, haja vista proporcionarem melhores resultados, sendo que $91,7 \%$ dos respondentes salientam aceitarem substituir a tecnologia que utilizam atualmente pela exigida pela agroindústria, desde que essa troca proporcione melhor remuneração."

Apesar da introdução de novas tecnologias (de manejo e ambiência) na produção de frango proporcionar benefícios, como redução de gastos com mão de obra, sua intensificação tende a ser uma ameaça à permanência dos pequenos produtores na atividade, haja vista a implantação de sistemas modernos de produção, como o Dark House, apresentar um elevado custo de investimento (Canever et al., 1998). Para o autor, "a adoção desses novos sistemas de criação requer volumes de recursos que em determinadas situações podem inviabilizar a permanência dos produtores na atividade e desestimular novos investimentos" (Canever et al., 1998, p. 1).

Esta pesquisa foi de caráter descritivo e com uma amostra por conveniência dos produtores, considerando a homogeneidade das práticas produtivas e contratuais com as incorporadoras. No entanto, não podemos deixar de considerar as suas limitações: a coleta de dados foi intencional, não probabilística e transversal no tempo. Isso leva a considerar restrições à generalização aos demais produtores da região. Os autores, conscientes das limitações do estudo, entendem que o tema requer novos estudos sob o caráter longitudinal e para um estrato maior.

Os resultados deste artigo apresentam algumas contribuições para o conjunto de conhecimento concernente à produção de aves, dado os valores empíricos e indicações dos principais fatores de sucesso empresarial. Os autores acreditam que este estudo pode contribuir para o conhecimento acadêmico e indicar a possibilidade de sua extensão em pesquisas científicas.

Sob o ponto de vista de implicações empresariais, este artigo representa uma oportunidade para que os agentes de desenvolvimento possam considerar os resultados como uma forma de tomada de decisão e melhoria das suas ações de assessoramento, e melhora econômica da região.

\section{Considerações finais}

A partir das informações obtidas através deste estudo verifica-se a importância econômica e social da avicultura de corte para a região estudada, sendo a participação do produtor integrado importante para o alcance de tais resultados.

Entretanto, para que o produtor venha a manter-se nessa atividade e obter sucesso nesse mercado, é importante que este tenha ciência de quais aspectos de sua atividade são responsáveis pela competitividade e/ou sucesso. Dessa forma, este estudo se propôs a analisar os fatores críticos de sucesso na produção de frango de corte, sob a ótica do produtor integrado da região da Grande Dourados, sendo analisados seis aspectos: estruturais, mão de obra, gestão, controle financeiro, biosseguridade e parceria integrada (Produtor-Agroindústria).

Como resultado, observou-se que tanto os produtores do cluster 1 como os do cluster 2 deram maior importância aos aspectos e subaspectos que interferem diretamente na produção e, consequentemente, na remuneração do produtor, assim como aqueles aspectos exigidos contratualmente pela integradora (saúde do frango, manejo, limpeza, normas e procedimentos de biosseguridade, entre outros). Diante disso, constatou-se que a integradora possui importante papel na obtenção desses resultados, já que, para ser parceiro da integradora, o produtor precisa se adequar a certas exigências, principalmente as preconizadas pelas legislações ambiental e trabalhista, além de procedimentos de biosseguridade.

Enfatiza-se a necessidade de orientação aos produtores quanto ao importante papel da gestão para o crescimento e desenvolvimento das propriedades aviárias, pois observou-se que tanto os produtores do cluster 1 como os do cluster 2 , ou seja, $75 \%$ dos entrevistados, 
salientam que o aspecto "gestão" apresenta pouca ou nenhuma importância para o sucesso da produção de frango.

Os resultados desta pesquisa estão em alinhamento com os achados de Guareski et al. (2019), Oliveira \& Caleman (2017), Zaluski \& Marques (2015), Figueiredo et al. (2006) e Ziebert \& Shikida (2004), no que concernem as seguintes constatações: (i) das vantagens advindas da integração para o produtor; (ii) de que o setor de produção de frango de corte apresenta monopólio por parte da integradora, na qual o integrado possui pouca ou nenhuma influência nas decisões, e (iii) de que os produtores possuem dificuldade de sair da parceria.

Apesar de este estudo ter obtido resultados distintos aos de Guareski et al. (2019) e Ziebert \& Shikida (2004) em relação à remuneração paga pelas agroindústrias aos produtores, considera-se salutar destacar a importância de a agroindústria criar um mecanismo de precificação dos custos de produção de fácil entendimento e que possa ser disponibilizado e atualizado constantemente ao integrado. Pois, embora os produtores tenham criado uma associação de avicultores integrados na região, com vista a dirimir conflitos entre as partes e tornar a parceria mais justa, a questão dos custos de produção ainda é tida como um fator de difícil consenso entre integrado e integradora. Para os produtores, a remuneração não é condizente à sua real produtividade.

Outro ponto a ser elencado é que, apesar da existência de algumas políticas em prol do desenvolvimento da atividade na região, como o Fundo Constitucional de Financiamento do Centro-Oeste (FCO) - utilizado, em geral, pelo produtor nos financiamentos dos aviários e equipamentos - e a isenção de ICMS, para aquisição de pellet e de sistema de energia fotovoltaica, de acordo com os produtores entrevistados ( $A, B, C, D, E, F, G$, e H), o setor ainda carece de políticas municipais, dado que os municípios onde os integrados possuem suas propriedades não dispõem de nenhum programa de incentivo à avicultura de corte.

A partir desses resultados, observa-se que o avicultor se apresenta exposto a diversos fatores relacionados à sua atividade, quer sejam internos ou externos. Dessa forma, ressalta-se a necessidade do mesmo ter ciência dos fatores críticos de sucesso de sua atividade, pois, a partir disso, conseguirá focar nas áreas que são fundamentais para o cumprimento de sua missão, assim como para o alcance dos resultados almejados.

\section{Referências}

Agência de Desenvolvimento Agrário e de Extensão Rural- AGRAER. (2019). Recuperado em 15 de julho de 2019, de http://www.agraer.ms.gov.br/.

Amaral, P. F. G. P., Martins, L. A., \& Otutumi, L. K. (2014). Biosseguridade na criação de frangos de corte. Enciclopédia Biosfera, 10(18), 664-685.

Araújo, M. J. (2009). Fundamentos de agronegócio. São Paulo: Atlas

Associação Brasileira de Proteína Animal - ABPA. (2017). Relatório anual 2017. São Paulo. Recuperado em 30 de janeiro de 2018, de http://abpa-br.com.br/

Associação de avicultores da zona da Mata - AVIZOM. (2014). Comunicado 001/2014. Diretoria da AVIZOM e PIF-PAF confirmam aumento de 7,94\% no valor do ponto. AVIZOM. Comunicado interno.

Bampi, V. (2014). Integração avícola brasileira, projeto sustentável. Avicultura Industrial. Recuperado em 27 de julho de 2020, de http://www.aviculturaindustrial.com.br

Barzel, Y. (2005). Organizational forms and measurement costs. Journal of Institutional and Theoretical Economics, 161, 357-373.

Bullen, C. V., \& Rockart, J. F. (1981). A primer on critical success factors (Vol. 69). Massachusetts: Center for Information Systems Research, Sloan School of Management.

Caldas, E. O. L., Lara, L. J. C., Cardeal, P. C., \& Matias, C. F. (2015). Análise econômica da produção de frangos de corte sob contrato de integração em pequenas unidades familiares. Organizações Rurais \& Agroindustriais, 17(3), 351-368.

Calinski, T., \& Harabasz, J. (1974). A dendrite method for cluster analysis. Communications in Statistics. Theory and Methods, 3(1), 1-27.

Canever, M. D., Chiuchetta, O., Santos Filho, J. I., \& Talamini, D. J. D. (1998). Mudanças tecnológicas na avicultura de corte: implicações sócio-econômicas. Revista de Política Agrícola, 7(1), 1-9. 
Cortina, J. M. (1993). What is coefficient alpha? An examination of theory and applications. The Journal of Applied Psychology, 78, 98-104.

Donastorg, A., Renukappa, S., \& Suresh, S. (2019). Evaluating critical success factors for implementing renewable energy strategies in the Dominican Republic. Renewable Energy, 149, http://dx.doi.org/10.1016/j.renene.2019.12.053

Empresa Brasileira de Pesquisa Agropecuária - EMBRAPA. (2019). Recuperado em 29 de agosto de 2018, de https://www.embrapa.br

Espíndola, C. J. (2012). Trajetórias do progresso técnico na cadeia produtiva de carne de frango do Brasil. Revista Geosul, 27(53), 89-113.

Fagundes, M. B. B., Fernandes, M. M., Figueiredo, A. M. R., \& Oliveria, D. V. (2018). A contribuição da avicultura de corte para o desenvolvimento do Mato Grosso do Sul. Revista Brasileira de Desenvolvimento Regional, 6(1), 109-136.

Figueiredo, A. M., Santos, P. A., Santolin, R., \& Reis, B. dos S. (2006). Integração na criação de frangos de corte na microrregião de Viçosa-MG: viabilidade econômica e análise de risco. Revista de Economia e Sociologia Rural, 44(4), 713-730.

Garcia, L. A. F., \& Ferreira Filho, J. B. de S. (2005). Economias de escala na produção de frangos de corte no Brasil. Revista de Economia e Sociologia Rural, 43(3), 465-483.

Gil, A. C. (2008). Métodos e técnicas de pesquisa social (6. ed.). São Paulo: Atlas, .

Guareski, A. H. P., Zachow, M., Fachin, G., \& Ribeiro, W. (2019). Sistema Contratual de Integração: Vantagens e Desvantagens percebidas pelos produtores de frangos de corte na região de Cafelândia - Paraná. Revista de Gestão e Organizações Cooperativas, 6(11), 43-60.

Hair, J. F., Black, W. C., Baldin, B. J., Anderson, R., \& Tatham, R. L. (2009). Análise multivariada de dados. Porto Alegre: Bookman.

Hansen, D. R., \& Mowen, M. M. (2003). Gestão de custos (R. B. Taylor, Trad., 1. ed.). São Paulo: Pioneira Thomson Learning.

Iguma, M., \& Zen, S. (2017). Custo de produção na cadeia produtiva de frango de corte brasileira. $A$ Revista do Avisite, 119. Recuperado em 5 de fevereiro de 2018, de http://www.revista doavisite.com.br/web/pub/ avisite/index2/\#page/28

Instituto Brasileiro de Geografia e Estatística - IBGE. (2016). Recuperado em 24 de abril de 2018, de http://www.ibge.gov.br

Kalamkar, S. S. (2012). Inputs and services delivery system under contract farming: a case of broiler farming. Agricultural Economics Research Review, 25, 515-521.

Leidecker, J. K., \& Bruno, A. V. (1991). Identifying and using critical success factors. Long Range Planning, $17,23-32$.

Lima, D. (2004). A programação matemática no planejamento de produção na relação avícola/aviário (Dissertação de mestrado). Universidade Federal do Paraná, Curitiba.

Malhotra, N. K. (2006). Pesquisa de marketing: uma orientação aplicada (L. Bocco, Trad., 4. ed.). Porto Alegre: Bookman.

Marconi, M. A., \& Lakatos, E. M. (2007). Técnicas de pesquisa. São Paulo: Atlas.

Marques, C. M. (2012). Mapas estratégicos para modelos de gestão voltados à competitividade da cadeia produtiva do frango de corte: um estudo na microrregião de Anápolis-GO (Dissertação de mestrado). Universidade Federal de Goiás, Goiânia.

Mato Grosso do Sul. Secretaria de Estado de Meio Ambiente e Desenvolvimento Econômico - SEMADE. (2015). Perfil estatístico de Mato Grosso do Sul (pp. 1-99). Campo Grande: SEMADE.

Mato Grosso do Sul. Secretaria de Estado de Meio Ambiente, Desenvolvimento Econômico, Produção e Agricultura Familiar - SEMAGRO. (2017). Recuperado em 15 de dezembro de 2018, de http://www.semagro.ms.gov.br/

Mizusaki, M. Y. (2007). Reestruturação produtiva na avicultura em Mato Grosso do Sul. Geosul, 22, 135154.

Mizusaki, M. Y. (2009). Território e reestruturação produtiva na avicultura (1. ed.). Dourados: UFGD.

Munaretto, L. F., Dellarmelin, S., \& Rosin, R. B. (2019). Proposta de metodologia de planejamento estratégico para pequenas propriedades rurais de base familiar. Revista do Desenvolvimento Regional, 16(1), 25-54. 
Oliveira, G. M., \& Caleman, S. M. Q. (2017). Avicultores Sul-Mato-Grossenses e a indústria avícola. Informe Gepec, 21(2), 24-41.

Otsuka, K., Nakano, Y., \& Takahashi, K. (2016). Contract farming in developed and developing countries. Annual Review of Resource Economics, 8, 353-376.

Paranhos, A. G. O., Adarme, O. F. H., Barreto, G. H., Silva, S. Q., \& Aquino, S. F. (2020). Methane production by co-digestion of poultry manure and lignocellulosic biomass: kinetic and energy assessment. Bioresource Technology, 300, 1-32.

Pinotti, R. N., \& Paulillo, L. F. O. (2006). A estruturação da rede de empresas processadoras de aves no Estado de Santa Catarina: governança contratual e dependência de recursos. Gestão \& Produção, 13(1), 167-177.

R Development Core Team. (2015). R: a language and environment for statistical computing. Vienna: $\mathrm{R}$ Foundation for Statistical Computing. Recuperado em 20 de fevereiro de 2018, de http://www.R project.org

Richetti, A., \& Santos, A. C. (2000). O sistema integrado de produção de frango de corte em Minas Gerais: Uma análise sob a ótica da ECT. Organizações Rurais Agroindustriais, 2(2), 34-43.

Richetti, A., Melo Filho, G. A., \& Fernandes, F. M. (2002). Sistema integrado de produção de frango de corte em área de assentamento de reforma agrária. Dourados: Empresa Brasileira de Pesquisa Agropecuária. Recuperado em 10 de julho de 2019, de http://ainfo.cnptia.embrapa.br

Rockart, J. F. (1979). Chief executives define their own data needs. Harvard Business Review, 57(2), 81-92.

Rodrigues, W. O. P., Garcia, R. G., Naas, I. A., Rosa, C. O., \& Caldarelli, C. A. (2015). Cadeia produtiva do frango de corte no Estado de Mato Grosso do Sul: uma análise de mercado. Organizações Rurais \& Agroindustriais, 17(1), 137-147.

Ruberto, I. V. G., Mareth, T., Paim, E. S. E., \& Pieniz, L. P. (2013). Contribuição da programação linear na gestão dos custos e na produtividade em uma propriedade rural. Custos e @gronegócio, 9(1), 185202.

Santana Júnior, J. R. (2009). Formação territorial da região da Grande Dourados: colonização e dinâmica produtiva. Geografia, 18(2), 89-107.

Schmidt, N. S., \& Silva, C. L. (2018). Pesquisa e desenvolvimento na cadeia produtiva de frangos de corte no Brasil. Revista de Economia e Sociologia Rural, 56(3), 467-482.

Serviço de Inspeção Federal - SFI. (2019). Recuperado em 15 de abril julho de 2019, de http://www.agricultura.gov.br

Sesti, L. (2004). Biosseguridade em granjas de frangos de corte: conceitos e princípios gerais. Recuperado em 19 de fevereiro de 2018, de http://www.cnpsa.embrapa.br

Simões, D., Ribeiro, J. P., Gouveia, P. R., \& dos Santos, J. C. (2015). Economical and financial analysis of aviaries for the integration of broilers under conditions of risk. Ciência e Agrotecnologia, 39(3), 240247.

Sistema Brasileiro de Respostas Técnicas - SBRT. (2007). Dossiê técnico: avicultura de corte. Instituto de Tecnologia do Paraná.

Stollenwerk, M. de F. L. (2001). Fatores críticos de sucesso. In T. Kira (Coord.), Inteligência organizacional e competitiva (pp. 189-207). Brasília: Editora UNB.

Superintendência do desenvolvimento do Centro Oeste - SUDECO. (2016). Fundo Constitucional de Financiamento do Centro-Oeste - FCO. Recuperado em 22 de fevereiro de 2018, de http://www.sudeco.gov.br/

Superintendência Federal de Agricultura de Mato Grosso do Sul - SFA/MS. (2013). Campo Grande.

Tarapanoff, K. (Org.). (2001). Inteligência organizacional e competitiva (pp. 303-326). Brasília: Editora UNB.

Vergara, S. C. (1998). Projetos e relatórios de pesquisa em administração (2. ed.). São Paulo: Atlas.

Williamson, O. E. (1985). The economic institutions of capitalism. New York: Free Press.

Zaluski, P. R. S., \& Marques, I. C. (2015). Vantagens e desvantagens do sistema de integração vertical na avicultura de corte. In Anais eletrônicos do $35^{\circ}$ Encontro Nacional de Engenharia da Produção. Fortaleza: ENEGEP.

Zanin, A., Oenning, V., Tres, N., Kruger, S. D., \& Gubiani, C. A. (2014). Gestão das propriedades rurais do Oeste de Santa Catarina: as fragilidades da estrutura organizacional e a necessidade do uso de controles contábeis. Revista Catarinense da Ciência Contábil, 13(40), 9-19. 
Ziebert, R. A., \& Shikida, P. F. A. (2004). Avicultura e produção integrada em Santa Helena, estado do Paraná: uma abordagem a partir da nova economia institucional. Agricultura, 51(1), 71-86.

Zylbersztajn, D. (1995). Estruturas de Governança e Coordenação do Agribusiness: uma aplicação da nova economia das instituições (Tese de livre docência). Faculdade de Economia, Administração e Contabilidade, Universidade de São Paulo, São Paulo.

Zylbersztajn, D., Marcos, F. N., \& Caleman, S. M. Q. (2015). Gestão de sistema de Agronegócios. São Paulo: Atlas. 
APÊNDICE 1. Tabela de frequências

\begin{tabular}{|c|c|c|c|c|c|c|c|c|}
\hline \multicolumn{2}{|r|}{ FATORES CRÍTICOS DE SUCESSO } & \multicolumn{7}{|c|}{ Escala de resposta } \\
\hline \multirow[t]{9}{*}{1} & $\begin{array}{l}\text { ASPECTOS ESTRUTURAIS E } \\
\text { MANEJO }\end{array}$ & & & & & & & \\
\hline & $\begin{array}{l}\text { Equipamentos em bom estado de } \\
\text { conservação, manutenção e } \\
\text { funcionamento }\end{array}$ & $0(0 \%)$ & $0(0 \%)$ & $0(0 \%)$ & $0(0 \%)$ & $0(0 \%)$ & $0(0 \%)$ & $\begin{array}{c}8 \\
(100 \%)\end{array}$ \\
\hline & $\begin{array}{l}\text { Equipamentos revisados antes do } \\
\text { alojamento dos pintainhos }\end{array}$ & $0(0 \%)$ & $0(0 \%)$ & $0(0 \%)$ & $0(0 \%)$ & $0(0 \%)$ & $\begin{array}{c}1 \\
(13 \%)\end{array}$ & $\begin{array}{c}7 \\
(88 \%)\end{array}$ \\
\hline & $\begin{array}{l}\text { Condições de acesso adequado } \\
\text { para caminhões da agroindústria }\end{array}$ & $0(0 \%)$ & $0(0 \%)$ & $0(0 \%)$ & $0(0 \%)$ & $1(13 \%)$ & $\begin{array}{c}5 \\
(63 \%)\end{array}$ & $\begin{array}{c}2 \\
(25 \%)\end{array}$ \\
\hline & $\begin{array}{c}\text { Políticas de bem-estar animal } \\
\text { dentro da granja }\end{array}$ & $0(0 \%)$ & $0(0 \%)$ & $0(0 \%)$ & $0(0 \%)$ & $0(0 \%)$ & $0(0 \%)$ & $\begin{array}{c}8 \\
(100 \%)\end{array}$ \\
\hline & $\begin{array}{c}\text { Qualidade da cama de frango } \\
\text { (influi diretamente no bem-estar da } \\
\text { ave) }\end{array}$ & $0(0 \%)$ & $0(0 \%)$ & $0(0 \%)$ & $0(0 \%)$ & $0(0 \%)$ & $\begin{array}{c}3 \\
(38 \%)\end{array}$ & $\begin{array}{c}5 \\
(63 \%)\end{array}$ \\
\hline & $\begin{array}{c}\text { Controle da temperatura } \\
\text { (aquecimento ou refrigeração) }\end{array}$ & $0(0 \%)$ & $0(0 \%)$ & $0(0 \%)$ & $0(0 \%)$ & $1(13 \%)$ & $\begin{array}{c}1 \\
(13 \%)\end{array}$ & $\begin{array}{c}6 \\
(75 \%)\end{array}$ \\
\hline & Controle da luminosidade & $0(0 \%)$ & $0(0 \%)$ & $1(13 \%)$ & $1(13 \%)$ & $0(0 \%)$ & $0(0 \%)$ & $\begin{array}{c}6 \\
(75 \%)\end{array}$ \\
\hline & Controle da ventilação & $0(0 \%)$ & $0(0 \%)$ & $0(0 \%)$ & $0(0 \%)$ & $0(0 \%)$ & $\begin{array}{c}1 \\
(13 \%)\end{array}$ & $\begin{array}{c}7 \\
(88 \%)\end{array}$ \\
\hline \multirow[t]{5}{*}{2} & ASPECTO MÃO DE OBRA & & & & & & & \\
\hline & Falta de mão de obra & $2(25 \%)$ & $0(0 \%)$ & $0(0 \%)$ & $0(0 \%)$ & $1(13 \%)$ & $\begin{array}{c}2 \\
(25 \%)\end{array}$ & $\begin{array}{c}3 \\
(38 \%)\end{array}$ \\
\hline & Falta de mão de obra qualificada & $2(25 \%)$ & $0(0 \%)$ & $0(0 \%)$ & $0(0 \%)$ & $1(13 \%)$ & $\begin{array}{c}1 \\
(13 \%)\end{array}$ & $\begin{array}{c}4 \\
(50 \%)\end{array}$ \\
\hline & Elevada rotatividade/absenteísmo & $2(25 \%)$ & $0(0 \%)$ & $1(13 \%)$ & $0(0 \%)$ & $1(13 \%)$ & $\begin{array}{c}1 \\
(13 \%)\end{array}$ & $\begin{array}{c}3 \\
(38 \%)\end{array}$ \\
\hline & $\begin{array}{l}\text { Falta de comprometimento dos } \\
\text { funcionários }\end{array}$ & $2(25 \%)$ & $0(0 \%)$ & $0(0 \%)$ & $0(0 \%)$ & $0(0 \%)$ & $\begin{array}{c}4 \\
(50 \%)\end{array}$ & $\begin{array}{c}2 \\
(25 \%)\end{array}$ \\
\hline \multirow[t]{9}{*}{3} & ASPECTO GESTÃO & & & & & & & \\
\hline & Planejamento operacional & $0(0 \%)$ & $0(0 \%)$ & $0(0 \%)$ & $0(0 \%)$ & $0(0 \%)$ & $\begin{array}{c}3 \\
(38 \%)\end{array}$ & $\begin{array}{c}5 \\
(63 \%)\end{array}$ \\
\hline & Dedicação exclusiva à atividade & $0(0 \%)$ & $0(0 \%)$ & $1(13 \%)$ & $0(0 \%)$ & $2(25 \%)$ & $\begin{array}{c}2 \\
(25 \%)\end{array}$ & $\begin{array}{c}3 \\
(38 \%)\end{array}$ \\
\hline & $\begin{array}{l}\text { Capacidade de manutenção dos } \\
\text { equipamentos }\end{array}$ & $0(0 \%)$ & $0(0 \%)$ & $0(0 \%)$ & $1(13 \%)$ & $0(0 \%)$ & $\begin{array}{c}2 \\
(25 \%)\end{array}$ & $\begin{array}{c}5 \\
(63 \%)\end{array}$ \\
\hline & $\begin{array}{l}\text { Conhecimento em tecnologia e } \\
\text { inovações em aviários }\end{array}$ & $0(0 \%)$ & $0(0 \%)$ & $0(0 \%)$ & $2(25 \%)$ & $0(0 \%)$ & $\begin{array}{c}3 \\
(38 \%)\end{array}$ & $\begin{array}{c}3 \\
(38 \%)\end{array}$ \\
\hline & $\begin{array}{c}\text { Uso de computador (gerar } \\
\text { planilhas de acompanhamentos, } \\
\text { relatórios) }\end{array}$ & $1(13 \%)$ & $1(13 \%)$ & $1(13 \%)$ & $1(13 \%)$ & $2(25 \%)$ & $\begin{array}{c}1 \\
(13 \%)\end{array}$ & $\begin{array}{c}1 \\
(13 \%)\end{array}$ \\
\hline & Habilidade em gerir pessoas & $0(0 \%)$ & $0(0 \%)$ & $0(0 \%)$ & $2(25 \%)$ & $1(13 \%)$ & $\begin{array}{c}3 \\
(38 \%)\end{array}$ & $\begin{array}{c}2 \\
(25 \%)\end{array}$ \\
\hline & $\begin{array}{l}\text { Capacidade de treinar seus } \\
\text { funcionários }\end{array}$ & $2(25 \%)$ & $0(0 \%)$ & $1(13 \%)$ & $0(0 \%)$ & $1(13 \%)$ & $\begin{array}{c}2 \\
(25 \%)\end{array}$ & $\begin{array}{c}2 \\
(25 \%)\end{array}$ \\
\hline & Habilidade de comunicação & $2(25 \%)$ & $0(0 \%)$ & $0(0 \%)$ & $0(0 \%)$ & $1(13 \%)$ & $\begin{array}{c}3 \\
(38 \%)\end{array}$ & $\begin{array}{c}2 \\
(25 \%)\end{array}$ \\
\hline
\end{tabular}


4 ASPECTO CONTROLE FINANCEIRO

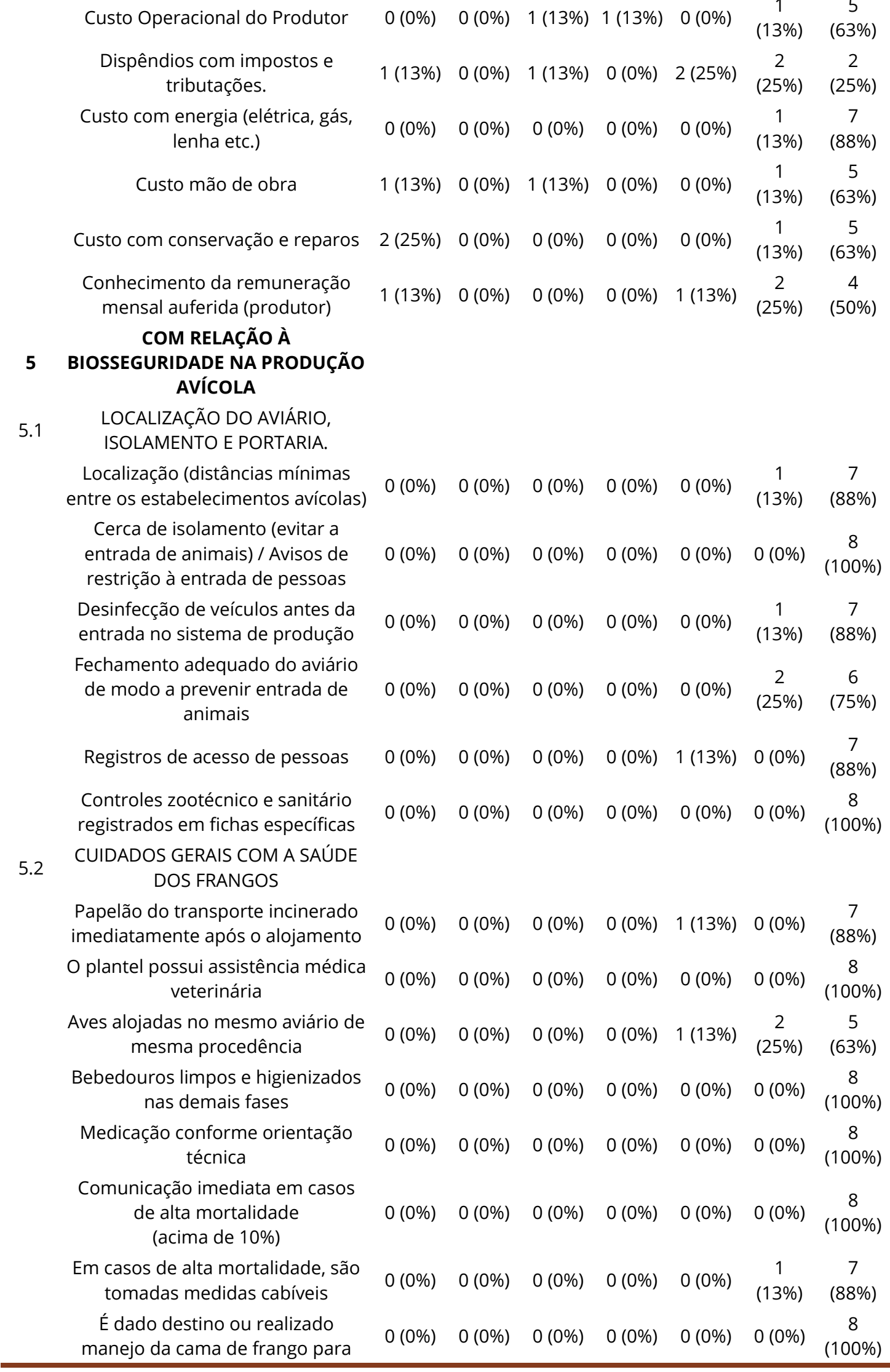




\section{FATORES CRÍTICOS DE SUCESSO}

impedir a criação de moscas e do cascudinho.

\section{LIMPEZA E DESINFECÇÃO}

Higienização do aviário é feita imediatamente após a saída do lote

$0(0 \%) \quad 0(0 \%) \quad 0(0 \%) \quad 0(0 \%) \quad 0(0 \%) \quad 0(0 \%) \quad \begin{gathered}8 \\ (100 \%)\end{gathered}$

A lavagem do aviário e equipamentos é realizada com água sob pressão

Caixas d'água e encanamentos lavados a cada lote

Após a limpeza e desinfecção, o

aviário fica fechado por pelo menos 10 dias sem a presença de animais.

Dois dias antes do recebimento dos pintos é feita nova desinfecção

Medidas de contenção contra roedores e insetos

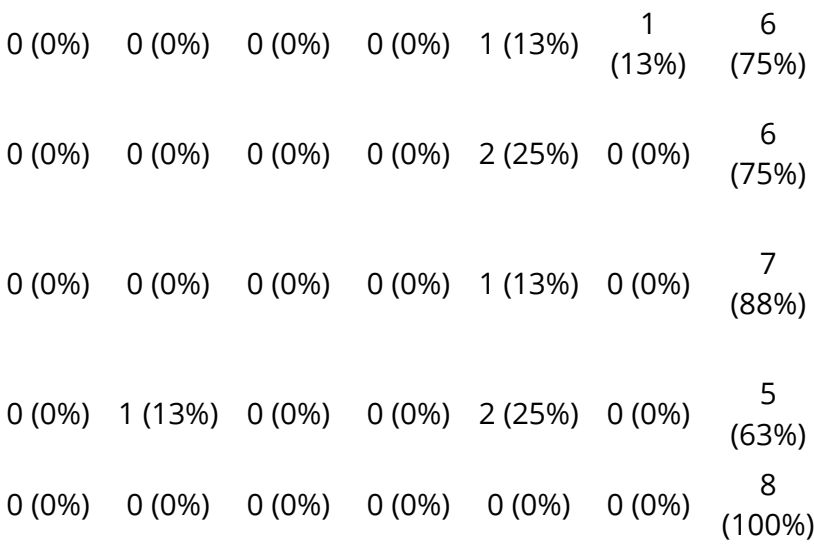

5.4 CAMA DO AVIARIO

A cama é de origem conhecida, livre de fungos e de tratamento químico utilizado para a preservação da madeira

A cama apresenta qualidade adequada, como, por exemplo, consegue absorver adequadamente a água que os pintos derrubam sobre ela e incorporar as fezes das aves Manejo adequado da cama durante a criação do frango

Correto tratamento da cama para reutilização

A cama a ser reutilizada é testada quanto a presença de microrganismo, como salmonela

$$
\text { Realização de compostagem }
$$

\section{HIGIENE E SEGURANÇA DO TRABALHADOR}

Funcionários são treinados e dão obediências às normas vigentes de higiene e segurança no trabalho

$$
0(0 \%) \quad 0(0 \%) \quad 0(0 \%) \quad 0(0 \%) \quad 0(0 \%) \quad \begin{array}{ccc}
1 & 7 \\
(13 \%) & (88 \%)
\end{array}
$$

$$
0(0 \%) \quad 0(0 \%) \quad 0(0 \%) \quad 0(0 \%) \quad 0(0 \%) \quad 0(0 \%) \quad \begin{gathered}
8 \\
(100 \%)
\end{gathered}
$$

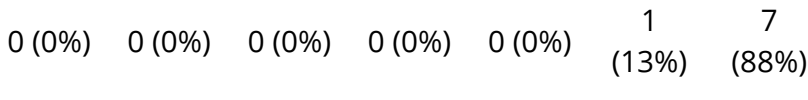$$
0(0 \%) \quad 0(0 \%) \quad 0(0 \%) \quad 0(0 \%) \quad 0(0 \%) \quad 0(0 \%) \quad \begin{gathered}
8 \\
(100 \%)
\end{gathered}
$$$$
1(13 \%) \quad 0(0 \%) \quad 0(0 \%) \quad 0(0 \%) \quad 0(0 \%) \quad \begin{array}{ccc}
4 & 3 \\
(50 \%) & (38 \%)
\end{array}
$$

$$
0(0 \%) \quad 0(0 \%) \quad 0(0 \%) \quad 0(0 \%) \quad 0(0 \%) \quad 0(0 \%) \quad \begin{gathered}
8 \\
(100 \%)
\end{gathered}
$$

Funcionários recebem orientação quanto ao uso correto dos equipamentos de proteção e aplicação de produtos

São fornecidos uniformes e demais assessórios para segurança e proteção

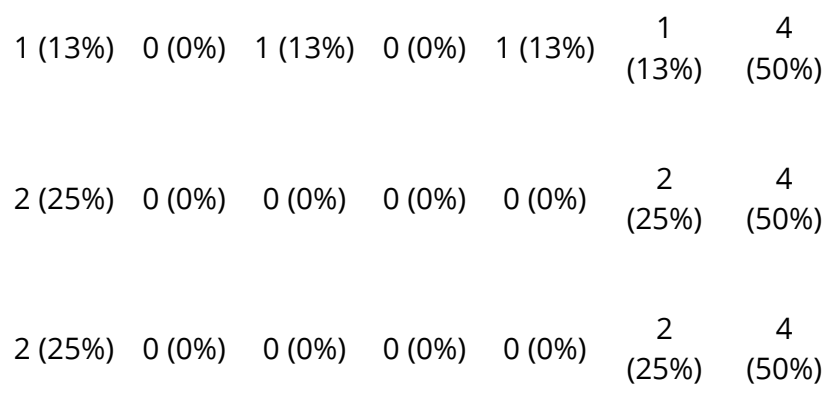




\section{FATORES CRÍTICOS DE SUCESSO}

Existe equipamento sanitário destinado para quem tem acesso aos aviários, com lavatórios, sabonete e bactericidas

As pessoas que entram nos aviários se paramentam corretamente

São disponíveis kits de primeiros socorros aos funcionários

Os produtos tóxicos utilizados no controle de pragas são estocados corretamente

6

\section{PARCERIA COM A}

AGROINDÚSTRIA

Meta do peso exigido pelos frigoríficos

Preços pagos pela Agroindústria

Qualidade da assistência técnica

Qualidade da ração

Atraso na reposição da ração

Atraso para recolhimento do frango para abate

Qualidade dos pintos recebidos
$1(13 \%) \quad 0(0 \%) \quad 0(0 \%) \quad 0(0 \%) \quad 0(0 \%) \quad \begin{array}{ccc}1 & 6 \\ (13 \%) & (75 \%)\end{array}$

$0(0 \%) \quad 0(0 \%) \quad 2(25 \%) \quad 1(13 \%) \quad 0(0 \%) \quad 0(0 \%)$

5

$(63 \%)$

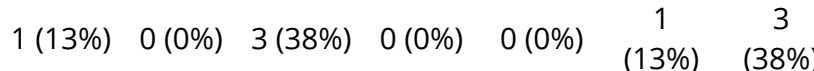

$0(0 \%) \quad 0(0 \%) \quad 0(0 \%) \quad 1(13 \%) \quad 1(13 \%) \quad \begin{array}{ccc}1 & 5 \\ (13 \%) & (63 \%)\end{array}$

$\begin{array}{ccccccc}0(0 \%) & 0(0 \%) & 0(0 \%) & 1(13 \%) & 1(13 \%) & 2 & 4 \\ & & & & & (55 \%) & (50 \%) \\ 0(0 \%) & 0(0 \%) & 1(13 \%) & 0(0 \%) & 0(0 \%) & (13 \%) & 6 \\ & & & & & & 6 \\ 0(0 \%) & 0(0 \%) & 2(25 \%) & 0(0 \%) & 0(0 \%) & 0(0 \%) & (75 \%) \\ 0(0 \%) & 0(0 \%) & 0(0 \%) & 0(0 \%) & 1(13 \%) & 2 & 5 \\ & & & & & 1 & 5 \\ 0(0 \%) & 0(0 \%) & 1(13 \%) & 0(0 \%) & 1(13 \%) & (13 \%) & (63 \%) \\ 0(0 \%) & 0(0 \%) & 0(0 \%) & 0(0 \%) & 0(0 \%) & 1 & 7 \\ 0(13 \%) & (88 \%) \\ 0 & 0(0 \%) & 0(0 \%) & 0(0 \%) & 0(0 \%) & 1 & 7 \\ 0\end{array}$

Fonte: Elaborado pelos autores (2019). 